\title{
Cipango
}

Cipango Cahiers d'études japonaises

$17 \mid 2010$

La péninsule retrouvée

\section{L'écriture des dieux : Hirata Atsutane et l'écriture coréenne}

De la nécessité d'une écriture autochtone de haute qualité à l'aube de la modernité

"The Script of the Gods": Hirata Atsutane and the Korean Script - The need for a High Quality Native Writing System in Pre-Modern Japan

\section{François Macé}

\section{Q OpenEdition \\ Journals}

\section{Édition électronique}

URL : https://journals.openedition.org/cipango/1125

DOI : 10.4000/cipango. 1125

ISSN : 2260-7706

\section{Éditeur}

INALCO

\section{Édition imprimée}

Date de publication : 30 juin 2010

Pagination : 107-149

ISBN : 978-2-85831-195-8

ISSN : $1164-5857$

\section{Référence électronique}

François Macé, «L'écriture des dieux : Hirata Atsutane et l'écriture coréenne », Cipango [En ligne], 17 | 2010, mis en ligne le 09 octobre 2012, consulté le 30 juin 2021. URL : http://journals.openedition.org/ cipango/1125; DOI : https://doi.org/10.4000/cipango.1125

Ce document a été généré automatiquement le 30 juin 2021.

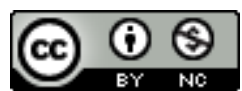

Cipango est mis à disposition selon les termes de la Licence Creative Commons Attribution - Pas d'Utilisation Commerciale 4.0 International. 


\section{L'écriture des dieux : Hirata}

\section{Atsutane et l'écriture coréenne}

De la nécessité d'une écriture autochtone de haute qualité à l'aube de la modernité

"The Script of the Gods": Hirata Atsutane and the Korean Script - The need for a High Quality Native Writing System in Pre-Modern Japan

\section{François Macé}

1 En 1942, Miyazaki Kohachirō 宮崎小八郎 publiait un ouvrage intitulé Jindai no monji 神 代の文字 (L'écriture du temps des dieux) ${ }^{1}$. Il y affirmait que les victoires japonaises en Chine et dans le Pacifique étaient dues à l'esprit japonais et à l'écriture des dieux²

2 L'évocation de l'esprit japonais, Yamato damashii 大和魂, n'a rien de surprenant dans cette période d'ultranationalisme. En d'autres lieux, on mit en avant l'esprit germanique ou l'esprit français. L'utilisation de l'écriture à des fins d'exaltation patriotique est par contre beaucoup plus étonnante. Il est vrai que celle qui est invoquée ici n'est pas une écriture platement inventée par un simple mortel, mais une série de signes remontant au temps des dieux, période consciemment située en dehors des temps historiques. Comme la lignée impériale, l'esprit japonais ou le Japon luimême, terre divine (shinkoku 神国), il y aurait donc une écriture japonaise remontant à la nuit des temps, plus ancienne et bien meilleure que tous les autres systèmes graphiques. Une écriture qui prend naissance avec les débuts de l'univers.

3 En un temps où la guerre en Chine avivait un sentiment de supériorité vis-à-vis de l'ancien pays modèle, et le mépris pour une civilisation qui n'avait pas su prendre le tournant de la modernité, l'affirmation, même dénuée de tout fondement, de l'existence d'une écriture indigène d'une très haute antiquité permettait de contrebalancer l'évidence historique de l'emprunt par le Japon à la Chine de très nombreux éléments de sa culture, dont bien évidemment son support lui-même, l'écriture.

4 Les exemples donnés par Miyazaki dans son ouvrage concernent en très grande majorité des noms de dieux ou de sanctuaires retranscrits en caractères du temps des 
dieux sur les talismans (ofuda お札) distribués (vendus) aux fidèles. Ces caractères sont dans presque tous les cas dans un style qui rappelle la cursive des sinogrammes, mais il s'agit toujours de syllabes que l'on peut superposer aux deux syllabaires communément utilisés. Avec quelques distorsions, ils se situent dans une lignée de caractères établie au cours de l'époque d'Edo par une des grandes figures des Études nationales, Hirata Atsutane 平田篤扸 (1776-1843).

$5 \quad$ Les jindai moji cités par Miyazaki ne sont pas les seuls à être connus. Il en existe en réalité une quantité assez impressionnante, dont la plupart n'ont eu qu'une diffusion très restreinte. Tous posent cependant problème à plusieurs niveaux: celui, tout d'abord, de leur existence même (pourquoi a-t-on éprouvé la nécessité de fabriquer une telle écriture ?) ; celui qui découle de leur utilisation ; celui aussi du choix de certains de ces caractères par Hirata Atsutane ; celui enfin de la diffusion de ces caractères.

\section{L'écriture des dieux au sein du shintō moderne}

Commençons par l'ouvrage de Miyazaki. On le trouve encore cité sur certains sites internet soit pour donner une touche mystérieuse à des sanctuaires en mal de publicité, soit de façon moins innocente, pour défendre la légitimité du sanctuaire de Yasukuni ${ }^{3}$. L'écriture que l'auteur préconise semble toucher un public beaucoup plus large que les autres écritures divines, qui se cantonnent à tel ou tel sanctuaire, ou à certaines traditions locales.

7 Miyazaki était chrétien. Il avait traduit en 1915, alors qu'il faisait un séjour d'étude aux États-Unis, une œuvre de David Smith, The Historic Jesus, sous le titre de Rekishiteki Yaso 歴史的耶蘇 ${ }^{4}$. Il était aussi spécialiste de littérature japonaise et se réclamait d'Ochiai Naozumi 落合直澄 (1840-1891). Autrement dit, il se situait dans un des courants principaux du shintō officiel et des Études nationales (Kokugaku 国学).

En effet, Ochiai Naozumi participa activement à la restauration de Meiji. Il avait étudié les Études nationales auprès de maîtres renommés, tel Mikannagi Kiyonao 御巫清直 (1812-1894), spécialiste des rites au sanctuaire d'Ise. Ochiai fut nommé « missionnaire » (senkyōshi 宣教師) du ministère des Affaires des dieux ${ }^{5}$. Puis il fit une carrière de desservant à Ise et finit par être promu daikyōsei 大教正, le plus haut rang de la hiérarchie des desservants du shintō. Ce fut donc un personnage considérable, auteur de nombreux ouvrages, dont un commentaire du Kojiki, le Kojiki kōden 古事記後伝 (Commentaire postérieur du Kojiki), dont le titre seul suffirait à le rattacher à la lignée de Motoori Norinaga 本居宣長 (1730-1801). Mais ce que les dictionnaires notent moins facilement, c'est qu'il publia aussi en 1888 un Nihon kodai moji kō 日本古代文字考 (Étude sur l'écriture antique du Japon) ${ }^{6}$. Son opinion n'aurait pu concerner qu'un petit cercle d'érudits, mais il avait été nommé en 1889 conférencier à l'Institut des Classiques impériaux ${ }^{7}$. Il put y former de nombreux desservants et répandre ses idées dans les sanctuaires de tout le Japon.

Ochiai, étant donnée sa position sociale, ne pouvait pas être un cas isolé. Ce n'était en aucun cas un original plus ou moins illuminé. Ainsi, ses idées sur l'écriture des dieux étaient-elles partagées par l'important Tanaka Yoritsune 田中頼庸 (1836-1897) ${ }^{8}$. Tanaka avait été chargé en 1871 de l'enquête sur les trois tertres du temps des dieux ${ }^{9}$. Il s'agissait d'intervenir dans le domaine mouvant qui se situe entre mythes (le temps des dieux) et histoire (événements qui laissent des traces dans le sol) pour ancrer la 
généalogie impériale dans l'histoire ${ }^{10}$. Il fut nommé en 1880 sous-directeur du Bureau du shintō (Shintō jimukyoku 神道事務局). Il faisait donc lui aussi partie de l'élite du shintō officiel.

Ochiai et Tanaka reprenaient, comme la majorité du personnel des sanctuaires, l'opinion du dernier grand maître autoproclamé des Études nationales, Hirata Atsutane ${ }^{11}$.

11 Malgré de si hauts patronages, l'écriture du temps des dieux ne connut pas un développement considérable. Elle ne servit pas, par exemple, à transcrire des textes qui auraient renfermé l'enseignement du shinto ${ }^{12}$. Pour le shintō officiel, les documents de référence restaient les classiques Kojiki, Nihon shoki et Kogoshūi, tous écrits en caractère chinois. L'important n'était donc pas la possibilité pour ces signes de transcrire un message singulier, mais l'existence de cette écriture même.

$12 \mathrm{Si}$, comme nous le verrons, tous les savants des études nationales ne partageaient pas les positions d'Atsutane, il est indéniable que l'influence de celui-ci fut prépondérante dans le monde du shintō $d u$ xIx ${ }^{e}$ siècle et du début du $x^{e}$ siècle. Or Hirata Atsutane attacha une grande valeur aux jindai moji. Pour lui, un certain nombre de documents anciens reproduisaient vraiment une écriture remontant au temps des dieux. Cela n'aurait guère tiré à conséquence s'il s'était agi d'un lettré de peu d'envergure. Mais Atsutane se trouvait dans une position stratégique. C'est en grande partie lui qui façonna le shintō qui allait devenir l'idéologie de référence à partir de Meiji. Son audience fut considérable. Il inspira ainsi directement certains acteurs de la restauration et leurs conseillers. ōkuni Takamasa 大國隆正 (1792-1871) fut l'un de ses relais ${ }^{13}$.

Le projet d'Atsutane était de grande ampleur. Il voulait reconstituer la tradition de l'Antiquité qui n'était parvenue jusqu'à son temps que sous forme morcelée, dans des textes parfois contradictoires. Au lieu de choisir le plus ancien, comme le fit Motoori son maître, il chercha, en choisissant les versions qui lui paraissaient authentiques, à restituer d'un état antérieur, le Koshi ${ }^{14}$. Son travail aboutit à une importante synthèse, dont il donna le texte incomplet en 1811 sous le titre de Koshi seibun 古史成文 (Texte de l'Histoire de l'Antiquité) ${ }^{15}$, et dont il entreprit un commentaire, le Koshiden 古史伝 (Commentaire de l'Histoire de l'Antiquité) ${ }^{16}$. Celui-ci faisait bien évidemment écho au Kojiki den 古事記伝 de Motoori, et posait de fait Atsutane en rival de son maître. Atsutane rédigea en 1819 un second ouvrage sur un thème proche, le Koshichō古史徵 (Preuves de l'Histoire de l'Antiquité ou éclaircissements sur le Document de l'Antiquité).

Dans cette recherche de l'Antiquité authentique encore pure de toute influence étrangère, de ce fameux «esprit chinois » (karagokoro 漢意) qu'exécrait Motoori, Atsutane était confronté à un fait massif: toute la tradition japonaise avait été transmise dans des textes écrits en chinois, ou du moins retranscrits en caractères chinois. Comment, dans ces conditions, la transmission n'aurait-elle pas été faussée ? Formé dans une société où l'écriture était la garantie de l'authenticité, il ne pouvait se contenter de l'hypothèse de la transmission orale, inévitablement dévaluée par les lettrés ${ }^{17}$. L'existence d'une écriture indigène remontant au temps des dieux lui offrait la possibilité de justifier l'authenticité des documents postérieurs, qui n'auraient fait que retranscrire en chinois ou en caractères chinois le message originel. 
15 Atsutane aborde la question de l'écriture du temps des dieux dans plusieurs de ses ouvrages. Il en donne un premier aperçu dans le Jinsei moji no ron ${ }^{18}$. Comme plusieurs des ouvrages d'Atsutane, le texte fut rédigé à partir des notes prises par ses disciples. Atsutane traite plus en détail de la question de l'écriture des dieux dans un texte légèrement postérieur, et qui renvoie à plusieurs reprises au Koshichō kaidaiki, le Shinji hibumi den ${ }^{19}$. Il y examine et confronte les différents documents et commentaires relatifs à ces écritures. L'ouvrage est préfacé par Yashiro Hirokata 屋代弘賢 (1758-1841), cité à plusieurs reprises, et qui partageait jusqu'à un certain point la même sensibilité au surnaturel qu'Atsutane ${ }^{20}$. Grand bibliophile, Yashiro avait rassemblé divers textes comportant des écritures du temps des dieux.

Ce sont ces deux ouvrages d'Atsutane qui vont donner leurs lettres de noblesse à l'écriture du temps des dieux. Or, l'écriture qu'il va retenir comme authentique parmi toutes celles qui circulaient à son époque partageait beaucoup de traits avec l'écriture coréenne. Il en convint lui-même. Sa position pose alors un double problème: celui, tout d'abord, de la revendication d'une écriture datant du temps des dieux, toute une part de la tradition érudite acceptant comme un fait évident l'absence d'écriture au Japon avant l'arrivée de l'écriture chinoise ; celui ensuite du choix d'une forme proche de l'écriture coréenne, problème directement lié à la question des modèles d'écriture disponibles et de leurs connotations intellectuelles et religieuses.

\section{L'absence d'une tradition sur la création de l'écriture} les épisodes faisant intervenir la divination. Le premier concerne Izanaki et Izanami, perturbés par la naissance de l'avorton Hiruko, et procédant à une divination pour savoir pourquoi leur premier enfant est si mal formé. Le second est plus connu, c'est celui de la caverne céleste. Confrontés à la terrible crise déclenchée par la réclusion d'Amaterasu, les dieux pratiquèrent la divination à partir d'une omoplate de cerf. Or la divination par scapulomancie utilisée au temps de la rédaction des deux ouvrages suppose un déchiffrement apparenté à celui de l'écriture. Pour les lettrés formés à la chinoise, il s'agissait bel et bien d'une forme d'écriture à déchiffrer. Pourtant, aucun des deux ouvrages ne fait de commentaires sur ce sujet. Ni le Kojiki ni le Nihon shoki ne voient d'inconvénient à le faire intervenir dans un temps qui ne connaît pas l'écriture. La sensibilité à l'anachronisme est une conquête récente au Japon comme ailleurs. chinoise bien évidemment, au règne de l'empereur ōjin. Ils précisent même le canal de 
cette introduction, le royaume de Paekche 百済 (le Kudara japonais), un des trois royaumes de la Corée antique. Selon le Nihon shoki:

Le roi de Kudara envoya Achiki (...). Achiki savait très bien lire les Classiques (...). Alors le souverain demanda à Achiki : "N'y a-t-il pas un autre savant plus fort que toi ?» (...) On fit donc venir Wani ${ }^{23}$.

Le Kojiki de son côté apporte une précision supplémentaire :

Il demanda encore au royaume de Kudara : "Si vous avez des hommes savants, offrez-lesnous ». C'est pourquoi on offrit un homme qui avait pour nom Wanikishi. On offrit en même temps que lui onze livres, les dix livres des Entretiens et le livre des Mille caractères ${ }^{24}$.

Comme l'historicité d'ōjin est fragile, il n'est pas question de prendre cette affirmation pour argent comptant. Tout ce que l'on peut dire, c'est qu'au début du viII siècle, on avait gardé le souvenir de l'arrivée de l'écriture dans un monde illettré. On sait de plus que les gens de l'archipel entretinrent des rapports diplomatiques avec la péninsule coréenne et la Chine depuis au moins le III siècle de notre ère. Ce qui suppose, à tout le moins, une confrontation avec l'écrit. Mais ce n'est pas le lieu de faire l'histoire de l'écriture au Japon ${ }^{25}$. Ce qui importe ici, c'est la perception de cette histoire. Pour les Japonais du vIII siècle, l'arrivée de l'écriture chinoise et des Classiques était considérée comme un événement majeur qui les faisait accéder à la civilisation.

Le Kojiki dans sa préface, le Nihon shoki dans ses annotations, parlent de livres, citent des écrits, mais sans autres précisions. Autrement dit, il ne peut s'agir que de documents rédigés comme eux à l'aide de caractères chinois. Le Kojiki fait bien intervenir l'oralité, avec le fameux Hieda no Are ${ }^{26}$ 稗田阿禮 à la fabuleuse mémoire. Mais il précise que celui-ci avait lu des anciens ouvrages, et surtout, il n'est jamais question d'une écriture indigène.

Ce qui passait sous ses yeux, il le disait à haute voix, ce qu'il entendait, il le gardait gravé dans son esprit. Aussi le souverain ordonna à Are de lire et d'apprendre la Succession des souverains et les Anciens événements des générations antérieures ${ }^{27}$.

24 À l'époque de Heian, quand on voulut donner une nouvelle version du récit des origines, on attribua à Shōtoku Taishi 聖徳太子 (574-622) ${ }^{28}$ et Soga no Umako 蘇我馬子 (?-626 ${ }^{29}$ la rédaction d'un ouvrage en chinois, le Sendai kuji hongi 先代舊事本紀 (Chronique principale des anciens faits des générations antérieures) ${ }^{30}$. Dans un autre texte de la même époque, le Kogoshūi 古語拾遗 (Recueil supplémentaire de récits anciens) ${ }^{31}$, achevé en 807, l'auteur, Inbe no Hironari 齊部廣成 ${ }^{32}$, précise dans sa préface :

À l'époque de la haute antiquité quand il n'y avait pas encore d'écriture (moji), puissants et humbles, jeunes et vieux, se transmettaient de bouche à oreille [les traditions], les paroles et les gestes des prédécesseurs restaient et n'étaient pas oubliés. Une fois l'écriture arrivée, on n'apprécia plus de parler des temps anciens ${ }^{33}$.

Cette affirmation, recueillie dans un ouvrage prestigieux, posera problème aux partisans de l'existence d'une ancienne écriture indigène, à commencer par Hirata Atsutane.

\section{Émergence de l'écriture du temps des dieux à l'époque médiévale : la divination}

Il faut attendre l'époque de Kamakura et l'émergence d'un courant religieux proclamant son autochtonie, le shintō, pour voir apparaitre les premières allusions à une écriture du temps des dieux. Celle-ci était désignée par les termes jindai moji 神代文 
字 ou kamiyo moji 神世字. Comme pour un grand nombre d'autres aspects du shintō médiéval, les caractères divins japonais ne peuvent se comprendre sans considérer le développement, dans le bouddhisme ésotérique, de croyances, pratiques et constructions théoriques autour des sons et des lettres. Qu'il suffise de rappeler l'importance des traités de Kūkai 空海 (774-835) relatifs à ce sujet ${ }^{34}$ et le rôle central, dans les rites, de la prononciation correcte de formules, mantra (shingon 眞言) ou dhāranī (darani 狍羅尼). On connaît aussi la méditation sur la lettre A 阿字 ${ }^{35}$. Le Japon, pays des dieux, ne pouvait pas ne pas avoir possédé lui aussi une écriture porteuse de la puissance des mots aussi forte que les lettres germes, auxquelles on reconnaissait la capacité d'évoquer, au sens fort du terme, les bouddhas et les bodhisattvas ${ }^{36}$.

Ce discours sur les lettres-sons se combina avec la croyance indigène aux kotodama $\overline{\bar{~}}$ 霊, «l'esprit des mots », qui considère, elle aussi, que les mots sont des sons efficaces ${ }^{37}$. Cette croyance, attestée dans de nombreux poèmes du Man.yō-sh $\bar{u}$ 萬葉集, au VIII ${ }^{\mathrm{e}}$ siècle donc, restera liée à la composition ou la prononciation de poèmes dans certaines circonstances jusqu'au XIX ${ }^{\mathrm{e}}$ siècle au moins.

Toutefois la première allusion connue à l'existence de caractères indigènes existant avant l'arrivée de l'écriture chinoise repose sur un raisonnement en apparence de bon sens et sans connotation ésotérique.

Dans le chapitre introductif du Shaku Nihongi 釈日本紀 (Nihon shoki commenté), Urabe Kanekata 卜部兼方 (actif au milieu du xIII e siècle) pose la question de l'origine des syllabaires japonais, les kana. Il évoque un texte de six ou sept feuillets, conservé parmi les ouvrages du palais, qui serait composé avec des « caractères de Hijin » (Hijin no ji 肥 人之字 $)^{38}$ ressemblant aux caractères sanscrits mais peu lisibles. Rappelant que les caractères chinois kanji 漢字 sont arrivés sous le règne d'ōjin, Kanekata se pose alors la question de l'existence de caractères japonais waji 和字 au temps des dieux. Comme il est question de divination (futomani 太占) quand Izanagi et Izanami s'interrogèrent sur la conduite à tenir après la naissance de Hiruko, comment auraient-ils pu la pratiquer sans écriture, se demande-t-il notamment ${ }^{39}$. Kanekata continue en supposant que Kōbō daishi (Kūkai) n'aurait fait que reprendre cette ancienne écriture waji pour composer son Iroha ${ }^{40}$. Il est important de noter ici que l'existence d'une écriture japonaise antérieure aux kanji a été, par un mouvement naturel, associée aux syllabaires kana dont on savait pertinemment qu'ils n'étaient pas anciens. L'intérêt de Kanekata pour cette question se comprend mieux quand on se rappelle qu'il appartient au clan des Urabe, c'est-à-dire des devins qui font remonter leur généalogie au temps des dieux, et dont l'ancêtre officia devant la caverne céleste. Devenus fonctionnaires dans l'État régi par les codes, les Urabe appliquaient la méthode chinoise de divination par la carapace de tortue depuis probablement la fin du VII ${ }^{\mathrm{e}}$ siècle.

À sa suite, beaucoup de commentateurs du Nihon shoki vont aborder la question de ces caractères. Tout au début de son commentaire des deux premiers livres du Nihon shoki, le Jindai no maki kuketsu 神代巻口訣 (Commentaire oral des livres du temps des dieux) ${ }^{41}$, Inbe no Masamichi 忌部正通 (dates inconnues) ${ }^{42}$ affirme que l'écriture du temps des dieux 神代文字se composait de caractères figurés, shōkei 象形, ce qui correspond à l'une des six catégories des caractères chinois (rikusho 六書), celle qui reproduit la forme d'un objet, un « idéogramme » donc, au sens courant du terme. Il pose d'autre part que si les caractères venus de l'étranger arrivèrent au Japon sous le règne d'ōjin, ce fut Shōtoku taishi qui remplaça les caractères japonais waji par les kanji ${ }^{43}$. 
31 Le fondateur de l'école shintō de Yoshida, Yoshida Kanetomo 吉田兼俱 (1435-1511), semble s'être inspiré de cet ouvrage. Les écrits de ce dernier personnage revêtent une importance particulière, car l'école qu'il fonda réussit peu à peu à dominer le monde du shintō aussi bien sur le plan théorique qu'administratif. Dans son propre commentaire du Nihon shoki, le Jinsho monjin 神書聞塵 $(1481)^{44}$, Kanetomo reconnaît que l'Iroha et les katakana sont bien les œuvres de Kūkai et de Kibi no Makibi 吉備真備 (695-735) ${ }^{45}$, mais il affirme que les cinquante sons du japonais remontent au temps des dieux et que de la Céleste lance précieuse Ame no nuboko 天之償矛 agitée par Izanagi et Izanami naquirent treize mille sept cent neuf caractères.

Il développe ensuite ses considérations de la sorte :

Au temps des dieux, quels caractères utilisait-on? Il n'y avait sans doute ni les katakana ni de caractères japonais. À ceci, que répondre? Au temps des dieux il y avait des livres. C'est un mystère. Aussi, il y eut une divination. En s'y conformant, les deux dieux Izanagi et Izanami firent leur serment et firent descendre la lance. Ils obtinrent ainsi une terre. S'étant unis comme époux, ils enfantèrent toutes choses. Quand on se demande d'où vient la divination, elle provient des transformations du Yin et du Yang et des cinq agents. Les lettres aussi viennent de la transformation des cinq agents. Les lettres sont une mutation naturelle $d u$ Ciel et de la Terre. Par cette mutation naturelle, Fuxi ${ }^{46}$, baissant et relevant la tête, écrivit un trait. C'est la mutation d'une partie de sa poitrine. S'il en est ainsi, ce qu'on appelle écriture est un. Aussi les Dix mille êtres étant apparus, le nombre de lettres est lui aussi important à cause du nombre des êtres. Dans un état d'esprit où aucune pensée irréfléchie n'apparait, soudain ils apparaissent et deviennent les trois entités (Ciel, Terre, Homme) et les six souillures, au point de devenir quatre-vingt-quatre mille grandes montagnes. Ainsi les lettres aussi devinrent nombreuses. La multitude des lettres, détentrices de l'esprit des $\hat{e}^{t}$ tres ${ }^{47}$, c'est le nombre des transformations des cinq agents. La quintuple transformation donne environ treize mille sept cent neuf lettres.

\section{La divination par la tortue}

Quand on brûle la tortue, le haut est le feu, le bas l'eau, la gauche le bois, la droite le métal, le milieu la terre. En se déformant, se tordant, rétrécissant, plus de dix mille lettres sont apparues. L'écriture du temps des dieux est connue par la divination de la tortue ${ }^{48}$.

Ce texte opère une synthèse assez hardie entre les mythes japonais, la conception chinoise de l'univers (cinq agents, trois entités), et des notions bouddhiques comme ichinen fushō一念不生 (un état d'esprit où aucune pensée irréfléchie n'apparaît) ou les six souillures (rokujin 六塵). Sans transition, il rattache l'écriture aux craquelures des carapaces de tortue lors de la divination. Il se poursuit sur des considérations liant le nom indigène du Japon, Yamato à la voyelle A, source de tout l'univers :

Sans en connaitre la lecture, on pourra lire [les caractères] 日本 (Yamato) hi no moto, " origine du soleil », si on lit à la japonaise. Les lire "Yamato ", qu'est-ce à dire? Yamato est le grand nom de notre pays. Quand des personnes de ce pays sont allées en Chine et qu'on leur a demandé le nom de leur pays, ne sachant rien répondre, ils dirent: notre pays quoi! (wagakuni ya). Or, "ya», et "wa», se confondent. Ce pays fut donc nommé Wa par la Chine. Ce pays est la source de la construction des trois mondes. La source de tous les phénomènes, c'est le fondement de la lettre A. Père, mère, au début du non créé, c'est A. Le début du Ciel et de la Terre, c'est aussi A. A, ka, sa, ta, na, ha, ma, ya, ra, wa, tous sont $A^{49}$. Horizontalement tous sont $A$. Dans la disposition des cinquante caractères, les caractères de tête vont tous vers A. La lettre A, c'est ya. A se confond [avec ya]. S'il en est ainsi, Yamato, c'est naturellement le nom de ce pays. C'est le pays de la source des êtres dotés d'émotion [êtres animés] et de ceux qui n'en ont pas [inanimés] ${ }^{50}$. 

entendue : les documents comportant des jindai moji étaient des faux ${ }^{55}$. Après s'être débarrassé, en quelques mots, des textes les plus grossiers fabriqués par les gens du shintō de Yoshida et de ceux, encore plus récents, qui imitaient les lettres des «Poils rouges»(kōmōji 紅毛字, les Hollandais), il prend la peine d'examiner ceux qui présentent des caractères proches de l'alphabet coréen genmon ${ }^{56}$. 
Parmi ceux-ci [les caractères dits du temps des dieux], il y en a trois dont le style est à peu près assuré. Ils ressemblent aux ridō $\overline{0}^{57}$, l'ancien style des caractères propres à ce pays (kokuji 国字) qui sont utilisés actuellement en Corée sous le nom d'écriture populaire genmon. Or un de mes amis, tout à sa découverte, pense faussement que ce sont vraiment des caractères du temps des dieux. Comme il m'a fait écouter sa théorie de son seul point de vue, c'était encore plus troublant ${ }^{58}$. Hunmong chahoe (jap. Kunmōjikai) 訓蒙字會 (Les caractères pour débutants) ${ }^{59}$, ouvrage de 1527 qui sera aussi utilisé par Hirata Atsutane. Il termine la démonstration en reproduisant et critiquant cinq exemples de ces caractères du temps des dieux. Dans le premier, qui provient d'un sanctuaire de la province d'Echigo, il note par exemple que la date donnée comporte un nom d'ère sous le règne de l'impératrice Suiko, alors que le premier nom d'ère connu au Japon est celui de Taika, trois règnes plus tard (p. 474). On comprend à la lecture de cette critique que désormais, l'anachronisme n'est plus toléré par une partie grandissante des lettrés. Ainsi, bien que reconnu sans hésitation comme un membre des Études nationales, Ban Nobutomo partageait un grand nombre de traits avec les lettrés sinisants d'Edo, notamment un sens critique très développé et une sensibilité d'historien ${ }^{60}$. Il travailla beaucoup sur les premiers textes historiques du Japon. Or la grande majorité des lettrés depuis l'Antiquité ne croyaient pas plus que lui à ces caractères sortis miraculeusement de la nuit des temps, mais pour des raisons probablement différentes : les lettrés de l'époque de Heian avaient encore une claire conscience de l'absence d'écriture au Japon avant l'arrivée des livres chinois, ceux de l'époque d'Edo réagissaient, eux, contre la croyance postérieure en une écriture des dieux.

Hirata Atsutane ne va pas hésiter à citer ces auteurs pour mieux les récuser: Kaibara Ekiken 貝原益軒 (1630-1724) ${ }^{61}$, Dazai Shundai 太宰春台 (1680-1747) ${ }^{62}$ notamment, ainsi que leurs sources : Ōe no Masafusa 大江匡房 (1041-1111) ${ }^{63}$, Miyoshi Kiyoyuki 三善清行 (847-918) ${ }^{64}$, sans oublier l'inévitable Inbe no Hironari, compilateur du Kogoshūi. Ceux-ci seront mobilisés de façon assez originale dans le Shinji hibumi den, où, après une première présentation de la véritable écriture des dieux, certains de leurs arguments sont présentés par des auditeurs et amènent une réponse du maître.

43 L'un des auditeurs commence par citer le Jigoshū 自娱集 (Recueil de mes divertissements) de Kaibara Atsunobu 貝原篤信65. La preuve évoquée de la nonexistence de l'écriture au temps des dieux est de nouveau le Kogoshūi et un ouvrage d'Ōe no Masafusa, le Hakozaki byōki 箱崎廟記 (Écrits sur le mausolée de Hakozaki, 1098) ${ }^{66}$. Comme ce sont des ouvrages de l'Antiquité, on peut se fier à leur témoignage, est-il dit. "C'est pourquoi dire qu'il existait des caractères nationaux dans la haute antiquité est fantaisiste $»^{67}$. Ce qui entraîne bien évidemment la réfutation d'Atsutane. Un autre auteur, tout aussi sérieux, Dazai Shundai, est plus brièvement cité68. Une dernière autorité est encore invoquée, Miyoshi Kiyoyuki, qui, dans un texte officiel, explique :

Dans la Haute Antiquité, tous les faits étaient transmis par oral. C'est pourquoi les faits des générations précédentes parfois se perdaient ${ }^{69}$.

En réponse, Atsutane se débarrasse sans ambages des deux lettrés de l'époque d'Edo: « l'argument des deux lettrés est sans le moindre fondement $»^{70}$. Il les qualifie un peu 
plus loin de «lettrés pourris» (kusarezusha 腐儒者). Les auteurs de l'Antiquité ne sont pas mieux traités : leur affirmation est «sans fondement 》(mukei 無稽), et les deux lettrés modernes ont eu le grand tort de les croire.

Tout en étant nés au Japon, ils dénigrent ce qu'on y apprend et méprisent notre pays. C'est extrêmement mesquin. Dans de vénérables sanctuaires subsistent actuellement des caractères de la haute Antiquité. Qu'ils existent est une certitude ${ }^{71}$.

\section{La caution d'un sceptique}

Malgré donc les arguments de l'analyse critique, les tenants de l'authenticité des textes en caractères du temps des dieux continuèrent à occuper des positions importantes. $\mathrm{Ce}$ fut le cas naturellement des gens de Yoshida qui propageaient les enseignements de leur fondateur Kanetomo. Or, bien que ces derniers continuassent à étendre leur emprise sur les sanctuaires, leur prestige intellectuel était en déclin. On ne connaît aucun grand traité de cette école à l'époque d'Edo. Les gens de Yoshida finirent par accueillir Hirata Atsutane comme conférencier, tant les thèses de l'école des Études nationales s'étaient répandues, rendant caduques les « shintō vulgaires » (zoku shintō 俗 神道), comme les nomme Atsutane en réprouvant leurs emprunts syncrétiques.

Par contre, les lettrés confucéens et leur approche positiviste avaient le vent en poupe. Aussi, on est étonné de retrouver parmi les tenants de l'écriture du temps des dieux, le sceptique Arai Hakuseki 新井白石 (1657-1725). Lui qui ne voyait pourtant, dans les récits du temps des dieux, que de l'histoire déformée par la légende ${ }^{72}$, a cru à une écriture japonaise antérieure à l'adoption des caractères chinois. Dans son ouvrage Dōbun tsūkō 同文通考 (Réflexions sur l'écriture commune), il aborde l'écriture des dieux à partir de la divination :

Il n'est pas faux de dire que la pratique de la divination en brûlant la tortue à l'époque des dieux dans notre pays est à l'origine des caractères des générations postérieures ${ }^{73}$.

Ce disant, il ne faisait que reprendre un argument ancien, développé depuis le Shaku Nihongi et repris par Kanetomo. Mais il poursuivait en affirmant que cela n'avait pu donner naissance à plus de dix mille caractères, comme le prétendait le même Kanetomo. Il continuait en récusant l'ancienneté des inscriptions sur fiche de bambou conservées dans les sanctuaires d'Izumo ou d'Atsuta. Il en restait donc à l'hypothèse de l'existence théorique d'une écriture des dieux, dieux qui, pour lui, n'étaient que des hommes d'un lointain passé, divinisés dans des récits légendaires. Son prestige de lettré servira toutefois de caution à la théorie d'Atsutane.

\section{Les croyants}

Bien que lui aussi de formation lettrée, Atobe Yoshiakira 跡部良顕 (1659-1729) de l'école Kikke 杼家神道, qui se réclamait du Suika shintō, introduisit, dans sa transmission, des caractères divins correspondant aux douze animaux du calendrier chinois. Une façon, dans la plus pure logique syncrétique, de donner une origine indigène à ce calendrier. Du point de vue de l'écriture du temps des dieux, il se situe dans la lignée d'Inbe no Masamichi et de ses caractères figurés. Ce type d'écriture sera récusé par Hirata ${ }^{74}$.

Les documents découverts dans de vénérables sanctuaires manquaient du prestige d'une tradition expliquant leur existence. C'est un texte du syncrétisme shintō- 
confucéano-bouddhique qui va donner une nouvelle impulsion à l'écriture des dieux : le Sendai kuji hongi daiseikyō 先代舊事本義大成經 (le Sutra sur le sens fondamental des anciens faits des générations antérieures) ${ }^{75}$. Parmi la masse de traditions qu'il rassemble, on trouve un passage qui relate qu'Amaterasu 天照太神 transmit à Ohonamuchi 大已貴神 le décret des 47 sons. Ce décret aurait été conservé dans un sanctuaire. Shōtoku taishi aurait retranscrit ces 47 sons en caractères chinois. Le Daiseikyō ne donne donc pas de jindai moji, mais la liste des sons. Il commence par hi, fu, $m i, y o, i, m u, n a, y a, k o, t o, m o, c h i$, ro, c'est-à-dire les premières syllabes des chiffres de 1 à $10000^{76}$, et se termine par un mystérieux ho, ke, re. Il indique que ce texte est utilisé pour l'apaisement des âmes. Le Daiseikyō est probablement à l'origine des Hifumi de l'époque d'Edo. Hirata Atsutane le connaissait et cite la liste en caractères chinois : 人含 道善命報名親兒倫元 etc., mais le qualifie de faux ${ }^{77}$.

51 La première mention du Hifumi en écriture des dieux remonte en 1779 au Shinkoku shinji benron 神国神字弁論 (Opinions sur l'écriture divine du pays des dieux), du moine Tainin 諦忍. Ce moine du temple Yahetosan Kōshōji 八事山興正寺 de la province d'Owari raconte qu'il s'est basé sur des livres secrets et les traditions d'antiques sanctuaires pour établir l'écriture des dieux qu'il présente aussi sous leur forme cursive. L'ordre est bien sûr celui du Hifumi. Dans le même texte, il donne aussi un exemplaire de l'écriture coréenne dans l'ordre de l'Iroha.

Hirata Atsutane cite à plusieurs reprises Tainin. Il commence par une partie de l'œuvre de ce moine, l'Iroha monben 以呂波問辨 (Discussion sur l'Iroha). La citation qu'il donne rapporte la transmission des 47 sons d'Amaterasu à Ohonamuchi. Le commentaire tombe durement :

Cette explication se trouve dans le Kuji daiseikyō qui fut forgé par Chōin de Kurotaki. C'est une explication qui repose sur un commentaire sans fondement ${ }^{78}$.

\section{La nécessité logique de l'existence de l'écriture des dieux}

53 Hirata, qui s'est proclamé disciple de Motoori, n'est pas un amateur. Il connaît très bien ce qui a été écrit sur la question de l'écriture des dieux et sait qu'il est des textes de fort mauvaise réputation. Lui qui prône un retour au shintō de l'Antiquité ne peut s'appuyer directement sur des ouvrages trop imprégnés du syncrétisme ordinaire qui règne depuis l'époque médiévale.

Dans son premier texte, Jinsei moji no ron, déjà évoqué, il cite les principaux auteurs qui ont traité de la question: les incontournables, Kanekata, Hironari, Masamichi mais aussi Ichijō Kanera 一条兼良79. Il se réclame aussi d'Arai Hakuseki, de Kamo no Mabuchi 賀茂真淵, et bien évidemment de son maître Norinaga. Il s'appuie encore sur son ami Ban Nobutomo. De ce point de vue, sa réflexion paraît sérieuse et bien documentée.

55 Ce qui m'apparaît comme le plus intéressant, c'est sa démarche. Comme son maître Motoori, il recherche la vérité des commencements, avant que la culture chinoise et son écriture aient tout déformé. Mais alors que Motoori va rechercher la langue ancienne derrière les caractères chinois, par une démarche philologique d'une grande rigueur, Atsutane veut justifier les traditions connues sous leur habillage chinois en 
posant l'existence d'un texte antérieur qui ne pouvait être écrit qu'avec une écriture japonaise. Il lui faut donc démontrer l'existence de cette écriture.

Dans le Jinsei moji no ron, texte assez court, il commence par faire la démonstration de l'existence d'un Nihon shoki en $k a n a^{80}$ antérieur à l'ouvrage que nous connaissons, écrit, lui, en chinois. Après une citation d'un commentaire (shiki 私記) du Nihon shoki cité dans le Shaku Nihongi où il est fait référence à un livre ancien (kohon 古本), il conclut :

L'ancien livre cité dans ce texte, c'est le Kana Nihongi ; le livre postérieur, c'est le Nihon shoki qui existe actuellement. Considérant l'importance accordée à ce livre ancien, plus qu'au Nihon shoki actuel, il faut connaitre l'ancien texte ${ }^{81}$.

Il donne ensuite un exemple de lectures et poursuit :

Une partie du Kana Nihongi cité par le shiki et le Shaku Nihongi utilisait des mots japonais en kana. La façon dont ils étaient transcrits est en gros semblable à celle du Kojiki. Il était plus ancien que cet ouvrage, c'était un texte écrit souvent en caractères pleins ${ }^{82}$.

Atsutane distingue donc trois sortes de kana, ceux des caractères chinois, ceux des caractères japonais et ceux de l'Iroha ${ }^{83}$. Bien qu'il ne le précise pas, on peut penser que les « kana des caractères chinois » peuvent désigner les katakana, ou plus probablement les man.yō gana. Les kana de l'Iroha sont, dit-il, « sans discussion » (agetsurahi nashi 論な L), l'œuvre de Kūkai (JMR, p. 17). Pour en arriver aux kana des caractères japonais, il commence par reprendre la citation du Shaku Nihongi sur la nécessité de l'existence de l'écriture pour procéder à la divination. En passant, il se moque d'une explication vulgaire (zokusetsu 俗説) qui explique l'invention de l'écriture en en attribuant l'idée à Ohonamuchi regardant les traces de pas d'oiseaux laissés sur le sable. Il fait tout de suite le rapprochement avec la tradition chinoise de Cangjie (ibid.).

Il invoque l'opinion d'Arai Hasuseki et la combine à celle d'Inbe no Masamichi pour établir l'existence de caractères imagés et de kana reproduisant les divers sons produits par la bouche ${ }^{84}$. De la même façon que les kana de Kūkai, purement phonétiques, dérivent des kanji, signes figuratifs, les anciens kana furent donc des signes phonétiques composés à partir de caractères figurés, ce qu'Inbe no Masamichi appelait shōkei. Il en veut pour preuve les six ou sept feuillets des hommes de Hi que mentionne le Shaku Nihongi. Il tire argument de la ressemblance que leur prête Kanekata avec les lettres sanscrites, bonji 梵字 (JMR, p. 20), pour souligner qu'il est difficile de croire que l'on aurait fabriqué de nouveaux caractères à l'époque de Tenmu (fin vII siècle), date à laquelle il situe le dépôt du texte à la bibliothèque du palais (ibid.).

Dans son premier texte évoquant la question donc, Atsutane ne présente aucun exemple d'écriture des dieux, mais prouve l'existence de tels signes par une nécessité logique. La pratique de la divination par scapulomancie implique l'écriture. Pour décrire cette écriture toutefois, il s'en tient à la seule comparaison avec les lettres sanscrites. Il n'est pas encore question de la Corée.

\section{L'écriture des dieux selon Atsutane}

C'est dans son second texte, légèrement postérieur comme on l'a dit, le Shinji hibumi den (Commentaire sur les Hifumi en caractères du temps des dieux) qu'il traite plus en détail de l'écriture des dieux. Il y examine et confronte les différents documents et commentaires relatifs à ces écritures. L'ouvrage est divisé en deux livres. Le premier se présente comme une analyse des problèmes soulevés par l'écriture du temps des dieux. Le cheminement du raisonnement n'est pas toujours facile à suivre. Assez 
régulièrement, des questions sont posées auxquelles « Atsutane répond », comme il est précisé dans le texte (Atsutane ifu 篤扸云字). Le second livre présente tous les exemples d'écriture pré-antiques qu'il a pu rassembler. Celles-ci sont classées en deux catégories, celles qu'il considère comme authentiques (treize), et celles qui lui paraissent douteuses ( $g i j i$ 疑字), une quarantaine.

61 Il commence son ouvrage par la citation du Kogoshūi qu'il réfute en quelques mots : « Je n'ai pas le temps maintenant de parler de maladresses de cette sorte $»^{85}$. Il continue en énumérant un certain nombre de textes conservés dans des sanctuaires ou des monastères. Il y distingue les caractères dans leur forme véritable (shinji 眞字) de ceux écrits en cursive (sōji 草字). Il reconnaît très vite (SHD, p. 2) :

Si l'on considère seulement les caractères véritables, ils ressemblent à ce qu'on appelle les caractères genmon de Corée. Ne serait-ce pas qu'à l'origine c'est en prenant ces genmon qu'on les [les jindai moji] a fabriqués ${ }^{86}$ ?

Mais il se rassure, en affirmant qu'on ne trouve pas de cursives de genmon (ŏnmun), alors que le Texte des hommes de Hi conservé au palais selon de Shaku nihongi était lui en cursive. Ce qui lui permet de conclure provisoirement :

Les genmon de Corée ne seraient-ils pas notre écriture du temps des dieux qui aurait été transmise dans les temps anciens dans ce pays, une écriture que les gens de ce pays en y ajoutant leur ruse ont fabriquée en la transformant ${ }^{87}$ ?

Il en apportera la démonstration dans la suite du texte. Pour le moment, il continue sa comparaison avec l'écriture coréenne, qu'il connaît à travers un ouvrage qu'il a emprunté à Yashiro Hirokata, le Hunmong chahoe, que connaissait aussi, comme nous l'avons vu (note 60), Ban Nobutomo. Il cite encore deux autres ouvrages comportant des caractères coréens ${ }^{88}$.

Un disciple aborde enfin les autorités des Études nationales dont il se réclame, Motoori et Kamo no Chōmei. Pour le premier, le disciple cite le passage du premier livre du Kojikiden $^{89}$, et conclut :

Et pourtant, ce sont des paroles qui ne convainquent qu'eux-mêmes. Kamo no Chōmei d'abord, puis Norinaga ont ouvert la voie de notre souverain pays, et pourtant ils ne se sont pas séparés de l'esprit chinois, ils sont restés dans le mélange du chinois et du japonais, c'est pourquoi ils n'ont pas compris clairement. Proférant des paroles qui ne convainquent qu'eux-mêmes, ils ont trompé les gens.

Devant cette attaque en règle, Atsutane réplique benoîtement :

Le grand homme d'Agatai (Mabuchi) et celui de Suzunoya (Norinaga) ont bien dit qu'il n'y avait pas d'écriture au temps des dieux, c'était une pensée grossière, mais ils n'avaient pas l'esprit chinois ${ }^{90}$.

Les maîtres se sont certes trompés. Mais il ne faut pas pour autant leur faire l'injure de les traiter d'esprits sinisés. Il en va de légitimité même d'Atsutane.

Dans la deuxième partie du premier livre intitulée Hifumi yoso jimari nana kowe 日文四 十七音 (Les 47 voix du Hifumi), Atsutane aborde directement l'écriture du temps des dieux. Le texte intitulé Hifumi remonte, comme nous l'avons vu, à un ouvrage un peu suspect le Sendai kuji hongi daiseikyō. Or, dans le Daiseikyō, le Hifumi est transcrit en kanji pris phonétiquement. Celui que donne Atsutane est bien évidemment en écriture des dieux. Il est probable que l'on a choisi cette liste de 47 sons donnés dans l'ordre du Hifumi pour bien distinguer l'écriture du temps des dieux des kana présentés dans l'ordre de l'Iroha, ou dans leur classement phonétique au sein du tableau des cinquante sons, présentations qui sont trop marquées historiquement et religieusement par le bouddhisme. 

réfute l'hypothèse d'Arai Hakuseki qui se référait à une version du Man.yōshū où les caractères hijin 肥人sont lus komahito, c'est-à-dire «homme de Koma » (Koma 高麗 désignant la Corée), pour dire que le Livre des hommes de Hi serait simplement un livre venu de Corée. Pour Atsutane, Hakuseki commettait ici un anachronisme, faute peutêtre de connaître la date de la création des genmon. Hunmong chahoe, sorte de lexique à classement méthodique qui donne la lecture en lettres coréennes des kanji. Il reproduit le passage où est expliqué le système de combinaison des lettres coréennes (SDH, p. 26-27).

La démonstration devient historique. Atsutane rappelle que les genmon 謗文furent inventés sous le règne de Sesō (Sejong) qui commença la $26^{\mathrm{e}}$ année de l'ère Ōei 應永 (1419) dans le comput japonais. Il fait ensuite un bref résumé de l'histoire de la Corée en commençant par la période des trois Han (Samhan 三韓) qui se transformeront en trois royaumes, ces trois royaumes formant la Corée contemporaine à l'auteur (Chosŏn). Or, souligne-t-il, ce pays est un pays barbare (ebisukuni 蕃國) géographiquement très proche du Japon. C'est là que descendit Susanowo quand il fut

Cipango, 17 | 2010 
chassé de la Haute plaine céleste. C'est encore là qu'arriva Mike.irenu no mikoto 三毛入 野命, frère de Jinmu, qui devint roi de l'un des trois royaumes, Shiragi (Silla 新羅, SDH, p. 28). Atsutane arrive enfin au règne de Chūai, et à la prétendue conquête des trois royaumes par l'impératrice Jingū. La conséquence en fut l'envoi de nombreux fonctionnaires japonais sur le sol coréen, et la venue de nombreux Coréens au Japon. Se référant au Tongguk T'onggam ${ }^{94}$, qu'il estime par ailleurs peu fiable, il note que c'est la $29^{\mathrm{e}}$ année du règne du roi Ch'ogo (jap. Shōko) 肖古王 du royaume de Kudara (Paekche 百済) que ce pays utilisa pour la première fois les caractères chinois alors qu'il n'avait pas d'écriture propre. La date correspond à la $60^{\mathrm{e}}$ année du règne de Nintoku au Japon (soit en 374 selon la chronologie traditionnelle). Il continue le même procédé avec les deux autres royaumes. Dans les trois cas, l'arrivée de l'écriture chinoise serait postérieure à sa venue au Japon sous le règne d'ōjin ( $S D H$, p. 29). Il y a donc une contradiction, déjà relevée - dit-il - dans le Wakan sansai zue 和漢三才圖會 ${ }^{95}(\mathrm{SDH}$, p. 30). Pour lui, l'important n'est pas là, mais dans l'absence d'une écriture propre (kokuji 國字) à la Corée depuis l'origine jusqu'à Sejong. À la question de la transmission des caractères japonais jusqu'à ce règne, Atsutane répond :

Comme cette région est depuis l'origine un pays où l'on prononce les mots oralement (kungo

訓語), il a dû très tôt utiliser les caractères de notre pays plutôt que l'écriture chinoise. En vérité, c'est une chose évidente ${ }^{96}$.

Autrement dit, si l'écriture chinoise est bien arrivée par l'intermédiaire de la Corée les Classiques japonais l'attestent - celle-ci aurait auparavant emprunté l'écriture japonaise, celle du temps des dieux. La démonstration repose uniquement sur un raisonnement qui se veut logique : a) les textes coréens disent que ce pays n'avait pas d'écriture avant l'écriture chinoise; b) l'écriture coréenne ressemble à l'écriture japonaise du temps des dieux; c) donc les Coréens ont emprunté l'écriture japonaise. Atsutane peut même donner la date : à partir de la conquête des trois royaumes par Jingū. Il semble complètement indifférent à l'absence de preuve matérielle ancienne.

À la fin du premier livre, Atsutane présente et explique les différences que l'on peut observer entre les caractères du temps des dieux et les caractères coréens. Pour lui, ces différences viennent tout simplement du temps qui a passé :

Tout en transmettant les caractères corrects de notre empire, les années s'accumulant et les générations passant, ils ont perdu l'usage de l'ancienne tradition. En fait, en se basant sur ces caractères et en les combinant avec le sanscrit, ils ont augmenté le nombre de caractères, c'est pourquoi il en est sorti des choses si maladroites ${ }^{97}$.

Le dernier argument mobilisé ensuite est particulièrement retors puisqu'il fait intervenir le premier grand nom des études philologiques, Keichū 契沖 (1640-1701) :

[Les Hifumi] présentent sans équivoque les sons exacts des deux colonnes ( $\mathrm{u}, \mathrm{wo}, \mathrm{wi}, \mathrm{we}$ wa) et (yu, yo, i, e, ya). Ils distinguent bien i /wi, et o/wo, et montrent de façon très exacte leur appartenance. S'ils avaient été fabriqués à partir des genmon auraient-ils été aussi exacts? Autrefois, quand on ne connaissait pas la distinction entre o/wo, i/wi, e/we, on considérait [ces distinctions] comme des choses inutiles. Il y a plus de sept cents ans, il en était particulièrement ainsi. Les gens savent que ces distinctions sont correctes depuis que récemment le maître de la loi Keichū les a éclaircies. Aussi les Hifumi ne peuvent avoir établi ces distinctions en ayant été forgées avant que le moine Keichū ne les éclaircisse ${ }^{98}$.

77 Comme le montrent ses références à des ouvrages coréens, Atsutane ne feint pas d'ignorer la ressemblance avec l'écriture coréenne. Il n'aurait pu le faire. La chose était évidente pour les lettrés qui avaient quelques lumières sur la Corée et son système d'écriture. Comme le fait remarquer Kim Moon Gil ${ }^{99}$, ce dernier n'avait rien de mystérieux pour des lettrés japonais qui avaient été en rapport direct ou indirect avec 
les douze ambassades coréennes qui s'échelonnèrent de 1607 à 1811. Le savoir sur la Corée et son système d'écriture remonte d'ailleurs à plus ancien. Il faut ici rappeler les deux expéditions militaires japonaises qui ravagèrent la Corée à la fin du $\mathrm{XVI}^{\mathrm{e}}$ siècle, en 1592 et 1597 plus exactement. Bien que le contexte fût dramatique, celles-ci mirent les Japonais en contact direct avec le monde coréen. Parmi le butin rapporté dans les bagages des troupes figuraient des livres (on a déjà parlé de celui ayant appartenu à Katō Kiyomasa), du matériel d'imprimerie, mais aussi des lettrés. On connaît l'histoire de Kang Hang (jap.: Kyō Kō 姜沉, 1567-1618), capturé lors de l'invasion de 1597, qui vécut trois ans au Japon où il eut des échanges avec Fujiwara Seika 藤原惺窩 $(1561-1619)^{100}$.

La venue des ambassades coréennes était également l'occasion d'échanges qui attestent de l'avidité intellectuelle de certains lettrés japonais, et de l'intérêt porté à la Corée par ce milieu à cette époque. On sait par exemple que le grand lettré de Kyōto Kinoshita Jun.an 木下順庵 (1621-1698) rendit visite au moins une fois à une des ambassades coréennes logées au Hon.nōji 本能寺 ${ }^{101}$, et se renseigna auprès d'elles sur les études confucéennes en Corée. Il aurait appris le hangŭ ${ }^{102}$. Parmi ses disciples figurait Arai Hakuseki, dont on a vu l'importance pour notre thème, et qui assista le shōgun Ienori lors de la venue de l'ambassade coréenne en $1709^{103}$.

Lors de la $9^{e}$ ambassade, en 1719, deux disciples d'Ogyū Sorai 荻生徂徠 (1666-1728) résidant à Nagoya, Kinoshita Jitsubun 木下實聞 (ou 實文) et Asahina Yukifuchi 朝比奈 之淵 (ou 文淵), allèrent à Nagoya à l'auberge où logeait l'ambassade pour apprendre le coréen à l'aide d'un manuel en ŏnmun, le Kaekkwan Ch'oegŏljip 客館崔桀集 (jap. Kyakukan saiketsushū, Recueil d'une grande élévation sur la maison des hôtes). Ils présentèrent par la suite l'écriture coréenne dans un ouvrage intitulé Wakan saisan shū 和館墔粲集 (Recueil plein de clarté du comptoir japonais), publié en 1719. Ce livre comportait en outre une transcription de l'Iroha en hangŭl. L'analogie avec l'écriture sanscrite, elle aussi alphabétique, y était notée. Ce fut probablement le premier texte au Japon à donner une présentation de l'écriture coréenne.

Un autre des disciples de Kinoshita Jun.an, Amemori Hōshū 雨森芳洲 (1668-1755), lettré de Tsushima, se rendit à Pusan et à Nagasaki et étudia le coréen. Il accompagna par deux fois les ambassades coréennes au Japon. Il ouvrit par ailleurs un cours de coréen en confectionnant un manuel, le Zen.itsu dōjin 全一道人 (L'homme de la voie complet, 1729). À la fin de sa vie, il écrivit un autre ouvrage du même type, le Kōrin shuchi 交隣須知 (Ce qu'il faut savoir pour les relations avec notre voisin), en utilisant notamment des proverbes coréens ${ }^{104}$.

81 On peut évoquer enfin Aoki Kon.yō 青木昆陽 (1698- ?), qui rédigea son propre manuel de coréen, le Kon.yō manroku ${ }^{105}$. Autrement dit, les lettrés japonais avaient à leur disposition, dès la première moitié $d u \mathrm{XVIII}^{\mathrm{e}}$ siècle, tous les outils nécessaires pour connaître le système d'écriture coréen ${ }^{106}$.

\section{Le déni de la réalité au nom de la foi}

Comme pour le Honkyō gaihen 本教外篇 (Supplément à l'enseignement fondamental), étrange ouvrage où Atsutane reprend presque mot pour mot des textes rédigés en chinois par les Jésuites, dont le célèbre Matteo Ricci ${ }^{107}$, on a ici aussi affaire à un refus de l'auteur de reconnaître un emprunt flagrant. Dans le cas présent, il est probable qu'il 
ne soit directement dû à Atsutane. Il est vain de crier au faussaire ou à la mauvaise foi. Si cela donne bonne conscience, cela n'aide pas à comprendre. La question me paraît profonde. Alors que Motoori avait réussi en grande partie à concilier sa foi inébranlable dans la vérité transmise par le Kojiki et une méthode philologique rigoureuse, Atsutane a basculé dans le registre religieux et n'a pas hésité à plier les textes dans le sens qu'il croyait être celui de l'ancien shintō. Ainsi, confronté à l'horreur du séjour des morts décrit dans le Kojiki, il s'inspira de ce qu'il savait du christianisme pour affirmer l'existence d'un au-delà (Kakuri yo 幽世 ou 隠世 : le Monde caché) promis à ceux qui ont su le mériter. Trouvant dans le christianisme une réponse plus satisfaisante que le simple constat proposé par Motoori Norinaga, Atsutane plaqua sans sourciller une conception consolante qui en était issue sur un terme assez vague employé dans le Kojiki et le Nihon shoki pour désigner l'après mort.

Il procéda de même pour l'écriture. Baignant dans une culture de l'écrit, il ne pouvait imaginer que l'ancienne religion japonaise ait pu se passer de l'écriture. Prisonnier des premiers textes qui projettent dans le passé des rites déjà marqués par l'écrit, il voit dans la pratique de la divination par l'omoplate de cerf ou la carapace de tortue, mais aussi dans la lecture des textes des prières (norito 祝詞), la preuve de l'existence d'une écriture antique antérieure à l'arrivée des caractères chinois. La seule question qui se posait alors pour lui, nous l'avons vu, était de savoir de quelle écriture il s'agissait.

À son époque, les Japonais connaissaient bien évidemment l'écriture chinoise. Tous savaient comment elle fonctionnait pour transcrire la langue chinoise. Ils savaient aussi que cette dernière était foncièrement différente du japonais et que l'écriture chinoise était inadéquate pour transcrire leur langue. Comme la majorité des lettrés, Atsutane ne remet pas en cause le caractère secondaire des syllabaires japonais, conçus à partir des kanji pour en faciliter la lecture, et pour transcrire directement le japonais. Il connaissait aussi les caractères indiens arrivés au Japon avec le bouddhisme, les bonji, qui s'écrivaient horizontalement et de gauche à droite. Il savait également comment fonctionnait l'écriture occidentale connue plus ou moins depuis le xvi siècle. Ces deux dernières écritures avaient l'avantage à ses yeux de ne pas être chinoises, et pour la deuxième de n'avoir aucun rapport avec le bouddhisme. Il faut noter en outre qu'elles sont alphabétiques.

Or, si les gens du shintō médiéval ont pu utiliser sans la moindre retenue des caractères sanscrits, cela n'était plus possible au début $\mathrm{du} \mathrm{XIX}^{\mathrm{e}}$ siècle pour un défenseur du retour à l'ancien shintō. La question de l'utilisation de l'écriture européenne ne se posait même pas. Quoiqu'on en pense, Atsutane est un auteur sérieux. Il ne se serait jamais lancé dans une aventure aussi ridicule que d'attribuer l'invention des caractères latins, ces lettres des Poils rouges, aux dieux japonais.

Restait donc l'écriture coréenne. Il y en avait des témoignages relativement anciens au Japon. Atsutane n'a pas eu, semble-t-il, à fabriquer des textes. Il s'est servi de ceux qui circulaient. Il leur donne toutefois un "coup de pouce " en faisant correspondre ce qu'il nomme la cursive avec les caractères du temps des dieux qui ressemblent à s'y méprendre à l'écriture coréenne.

La proximité géographique et les récits du Kojiki et du Nihon shoki qui relatent la conquête de la Corée par l'impératrice Jingū ont certainement joué un rôle non négligeable. Ils lui ont permis d'inverser simplement le sens de l'emprunt. Ce qui est plus aisé que de bâtir complètement une hypothèse, ou de justifier l'ancienneté d'un système graphique entièrement arbitraire. 
En effet, Atsutane n'abandonne jamais un certain sens critique. C'est probablement pour cette raison qu'il parut longtemps, et à beaucoup, crédible. Il a bien su reconnaître parmi tous les exemples d'écritures des dieux qui circulaient, celle qui fonctionnait vraiment comme une écriture, pour la bonne raison que cela en était réellement une.

On peut donc ajouter un autre argument à son choix : celui de la simplicité et de la logique de l'écriture coréenne. Celle-ci pouvait en effet facilement retranscrire le japonais. C'était la solution idéale pour s'échapper à l'emprise des caractères chinois, «qui sont si nombreux que les Chinois eux-mêmes ne peuvent tous les apprendre en une vie, ce qui fait rire les Occidentaux $»^{108}$.

o Il est remarquable qu'Atsutane se soit concentré sur l'existence d'une écriture divine et sur son système sans s'intéresser au contenu des textes écrits à l'aide de cette écriture. La quasi-totalité des exemples qu'il donne retranscrit le Hifumi. Or, comme nous l'avons $\mathrm{vu}$, ce texte ne fait pas sens. Le Sendai kuji hongi daiseikyō lui attribuait une efficace dans le cadre d'un rituel. Atsutane n'aborde pas la question. Cela ne semble pas l'intéresser.

91 Il ne s'est pas non plus servi de cette écriture pour révéler une nouvelle version des récits du temps des dieux, comme le feront d'autres « découvertes » dans la deuxième moitié du XIX siècle $^{109}$.

Même s'il ne fait pas allusion à la réflexion sur la langue qui sous-tend la création de l'écriture coréenne, avec une analyse des points d'articulation des consonnes, il me paraît clair qu'Atsutane fut conquis par la beauté du système. Une telle écriture, si parfaite, si logique, ne pouvait venir que du temps des dieux et du Japon.

\section{La postérité de Hirata Atsutane}

93 La simplicité d'utilisation des jindai moji sera reconnue dans des contextes très différents. Léon de Rosny les utilise pour donner la lecture des kanji dans sa traduction des premiers livres du Nihon shoki ${ }^{110}$. Il se sera probablement servi d'un des commentaires du Shoki issus de l'école de Hirata.

D'autre part, les jindai moji étaient suffisamment présents et appréciés dans le Japon de Meiji pour que l'on songe à eux dans ce contexte de modernisation. Dans la grande effervescence de cette époque, Mori Arinori 森有礼 (1847-1889) proposa de supprimer caractères chinois et syllabaires japonais pour adopter l'écriture européenne, allant même jusqu'à prôner la suppression du japonais (Nihongo haishiron 日本語廃止論). Un autre membre de la Société de l'an6 de Meiji (Meirokusha 明六社), Nishi Amane 西周 (1829-1897), soutenait lui aussi qu'il fallait écrire le japonais à l'aide de caractères occidentaux ${ }^{111}$. Dans le même ordre d'idée, le pasteur méthodiste Hiraiwa Yoshiyasu (1856-1933), qui avait séjourné au Canada, proposa dans la revue chrétienne Rikugō zasshi 六合雑誌 de ne pas adopter des caractères étrangers mais d'utiliser l'écriture japonaise, celle qu'avait prônée Atsutane, l'écriture du temps des dieux ${ }^{112}$. Cette proposition fit long feu. Il n'en reste pas moins, comme nous l'avons vu au début de cet article, que les jindai moji dans leur version Urabe Ahiru, celle qu'avait retenue Atsutane, demeurèrent inséparables du shintō officiel jusqu'en 1945. Un autre chrétien, Miyazaki, s'en fit le chantre en 1942. La parenté de cette écriture avec les caractères coréens ne faisait pourtant plus de doute depuis longtemps. Ironie de l'histoire : À la même époque, le gouvernement japonais menait une politique de plus en plus violente 
contre la culture coréenne et le hangŭl, qui était devenu le symbole de l'identité coréenne bafouée.

Le détournement de leur écriture par les Japonais n’a pas laissé les Coréens indifférents. Ces derniers n'ont guère été sensibles à l'honneur de voir leur écriture attribuée aux dieux de leurs colonisateurs. Dès l'époque de la domination japonaise, Kim Yun-gyŏng 金允経 se serait insurgé :

Au Japon, depuis deux ou trois cents ans, les spécialistes du shintō et quelques personnes qui avaient un cour de patriote, considérant avec honte que leur pays n'avait pas d'écriture dans l'Antiquité, gravèrent secrètement sur la pierre des caractères qui imitaient les caractères coréens et l'enfouirent dans la montagne. S'y rendant exprès avec une autre personne, ils déterrèrent la pierre comme s'il la découvrait. Ensuite, considérant ces caractères, ils prétendirent que c'était l'écriture du temps des dieux. Ce n'est pas tout, ils allèrent jusqu'à prétendre que les Sons corrects pour l'instruction du peuple ne sont autres que ces caractères du temps des dieux transmis en Corée $e^{113}$.

Un peu plus tard pourtant, un chercheur coréen en poste dans une université américaine affirmait, dans un article de 1974, qu'il y avait eu une écriture indigène en Corée avant le roi Sejong, et que celle-ci aurait pu venir d'un emprunt à l'écriture d'Ahiru ${ }^{114}$ !

\section{En guise de conclusion: sur l'actualité de l'écriture des dieux}

Après guerre, plus aucun chercheur sérieux ne soutenait l'authenticité des jindai moji. Yamada Yoshio 山田孝雄 pensait en 1952 avoir apporté la dernière réfutation dans ses articles regroupés sous le titre : "Mémoire sur les soi-disant caractères du temps des dieux $»^{115}$.

Pourtant les jindai moji ont la vie dure. Délaissant les formes trop régulières chères à Atsutane, ils se sont maintenus sous des aspects plus insolites. Un certain Matsumoto Yoshinosuke 松本善之助 ${ }^{116}$ a par exemple réussi à réunir suffisamment de fonds et de soutiens pour publier plusieurs ouvrages sur la «Tradition de Hotsuma» (Hotsuma tsutae ホツマツタヘ 秀眞政卮紀), qui comporte un texte assez long retranscrit en caractères des dieux accompagnés de caractères chinois. Ce texte, qui daterait de 1782, fut redécouvert en 1992. Matsumoto l'a fait traduire en anglais ${ }^{117}$ et en a donné également une édition luxueuse dédiée au prince Naruhito de la maison de Hiro (Hiro no miya Naruhito shinnō 浩宮徳仁親王) en $1993^{118}$.

Sur un autre registre, d'allure plus académique, Fujiyoshi Yoshio 藤芳義男 ${ }^{119}$ réfute le caractère originel de l'écriture d'Ahiru (elle ne remonterait qu'au vil siècle), pour mettre en avant les caractères dits « de la caverne » (qui remonteraient au tout début de notre ère). Ce qui amène de nouvelles réfutations, par exemple celle de Tanaka Katsuya 田中勝也 ${ }^{120}$ chez le même éditeur, en 1980 !

Il n'y a pas de raison que cela cesse. Il existera toujours des amateurs de traditions secrètes. Mais les enjeux sont désormais beaucoup moins importants. Il ne s'agit plus que de satisfaire un certain public avide de mystères et de choses cachées depuis la création du monde.

On aurait pu croire que le hangŭl resterait désormais cantonné à la transcription du coréen et qu'il n'attirerait plus d'autres amateurs en dehors de la péninsule. Les langues non encore écrites, celles des hommes comme celles des dieux, préfèrent 
désormais l'alphabet latin. Pourtant, en 2009, une population de l'île de Buton, dans l'archipel des Célèbes, en Indonésie, a choisi le hangŭl pour transcrire sa langue (le cia cia) qui n'avait jamais été mise par écrit ${ }^{121}$. Si des récits mythiques bénéficient de cette transcription, le hangŭl deviendra une fois encore une écriture des dieux.

\section{NOTES}

1. Kasumigaseki shobō霞ヶ関書房, republié chez le même éditeur en 1974. La lecture monji est donnée par le catalogue de la bibliothèque de la diète. Sur l'auteur voir ci-dessous. Les auteurs qui ont écrit sur les jindai moji ne font presque jamais de distinction entre caractères, lettres, écritures, styles d'écriture. J'ai essayé de traduire de façon appropriée selon le contexte avec souvent beaucoup d'hésitation.

2. J'ai pris connaissance de ce livre grâce à l'article de Kim Moon Gil (Kim Mun-gil) 金文吉, 《Jindai moji to nihon kirisuto kyō - Kokugaku undō to kokuji kairyō » 神代文字と日本キリスト 教一国学運動と国字改良 (L'écriture du temps des dieux et le christianisme japonais - Le Mouvement des études nationales et l'amélioration de l'écriture nationale), Dai hyakugojū kai Nichibunken föramu 第 150 回 日文研フォーラム, Kokusai nihon bunka kenkyū sentā 国際日本 文化研究センター, 2002.

3. Site du Cours de Kudan (Kudanjuku 九段熟) consulté le 7 mai 2010 : http://9112.teacup.com/ bicchu/bbs/780. Le Cours de Kudan (quartier où se situe le Yasukuni jinja) se propose d'œuvrer pour asseoir la légitimité du Yasukuni en respectant la maison impériale et le Grand sanctuaire d'Ise.

4. Publié par le Nihon kirisutokyō kōbun kyōkai 日本基督教興文協会. L'original anglais a été publié à New York et Londres par Hodder et Stoughton en 1912.

5. Au tout début de Meiji, on restaura un ministère des Affaires des dieux, en même temps que d'autres institutions de l'Antiquité. Une de ses fonctions, outre le contrôle des sanctuaires et des desservants, fut de promouvoir le Grand enseignement (Taikyō 大教), celui de la Grande déesse Amaterasu, visant à promouvoir le culte impérial. Voir Josef Kyburz, "Telle une bouffée de vent divin. Le culte d'Ise au début de l'ère Meiji », Cipango - Cahiers d'études japonaises, $\mathrm{n}^{\circ} 7$, Inalco, automne 1998, p. 181-204.

6. Cité par Kim Moon Gil, op. cit. p. 46-49.

7. Le Kōten kōkyūjo 皇典講究所 avait été créé en 1882 pour former les futurs desservants des sanctuaires. Il organisa la compilation de la grande encyclopédie thématique Koji ruien 古事類苑 (Le Jardin classé des faits anciens) qui est toujours fort utile pour l'étude du Japon d'avant Meiji.

8. Sur sa position vis-à-vis des jindai moji, voir le Shintō jiten 神道事典 (Dictionnaire du Shintō), compilé par le Kokugakuin daigaku nihonbunka kenkyūjo 国学院大学日本文化研究所, édition en format réduit, Kōbundō 弘文堂, 1999, p. 389. Tanaka s'opposa à Senge Takatomi 千家尊福 (1845-1918) du sanctuaire d'Izumo au moment de la querelle qui divisa le monde des sanctuaires entre les partisans d'Ise et ceux d'Izumo. En 1882, il fonda une nouvelle religion centrée sur Ise, le Jingūkyō 神宮教. Il a laissé des éditions annotées du Kojiki, du Nihon shoki et du Kogoshūi.

9. Jindai sanryō 神代三陵, tertres attribués à Ninigi, Hikohohodemi et Ugayafukiaezu, les trois générations divines qui précèdent l'empereur Jinmu, le premier empereur humain de la tradition, un personnage de légende pour les historiens. Ces tertres n'avaient jamais fait l'objet de beaucoup d'attention jusqu'à l'époque de Meiji. Ils figurent bien au début de la liste des tertres 
impériaux de l'Engishiki 延喜式 (Règlements de l'ère Engi, 927), mais à la différence des autres tertres leur localisation se limite au nom de la province. De plus, aucun foyer ne leur est attribué. Enfin, les défunts ne sont pas célébrés sur place, mais à partir de la province de Yamashiro, celle de la capitale; Engishiki chūhen 延喜式中篇, Shintei zōho Kokushitaikei 新訂増補国史大系, Yoshikawa kōbunkan 吉川弘文館, 1977, p. 547.

10. Cf. François Macé, «De l'Inscription de l'histoire nationale dans le sol. À la recherche des tombes impériales dans la deuxième moitié d'Édo », in J.-P. Berthon, A. Gossot (éd), Japon pluriel 3 - Actes du troisième colloque de la SFEJ, Arles, Éditions Philippe Picquier, 1999, p. 173-179.

11. Il se situa lui-même dans la généalogie des principaux savants des Études nationales, les "Quatre grands» Kokugaku shitaijin 国学四大人, qu'il faisait commencer par Kada no Azumamaro 荷田春満 (1669-1736), suivi de Kamo no Mabuchi 賀茂真淵 (1697-1769), puis du grand maître Motoori Norinaga (1730-1801) pour s'achever bien évidemment avec lui.

12. Nous verrons que certains se serviront de ces caractères pour faire connaître des traditions secrètes, mais leur audience semble avoir été très restreinte.

13. Ōkuni est l'un des grands noms des études nationales de la fin de l'époque d'Edo. Il traita lui aussi de l'écriture des dieux à travers deux ouvrages en particulier : le Shinjigen 神字原 (Le champ des caractères des dieux) et le Shinji shōkō oyobi kōyo 神字小考及考餘 (Modestes réflexions sur l'écriture des dieux suivies d'un supplément aux réflexions), en 1840.

14. 古史, l'Histoire de l'Antiquité si l'on suit le sens des caractères chinois, ou le Document de l'Antiquité si l'on suit la lecture japonaise Inishihe no fumi. Antiquité est à comprendre ici comme l'Antiquité première, celle des commencements.

15. Seuls les trois premiers livres, qui traitent du temps des dieux, ont été publiés, en 1818. Pour l'auteur, il s'agissait des plus importants, ceux des commencements.

16. Il commença le manuscrit vers 1812 et continua à y travailler jusqu'à sa mort, le laissant inachevé. C'est un de ses disciples qui le terminera. Il ne sera publié qu'en 1911.

17. Cf. infra la citation de Miyoshi Kiyoyuki et la position d'Inbe no Hironari.

18. Ou Kamiyomoji no agetsurahi 神世文字の論 (Discussion sur l'écriture du temps des dieux), achevé en 1818 ou 1819. En lecture japonaise, jindai 神代 et jinsei 神世 se lisent de la même façon kamiyo. Le titre de l'ouvrage sera désormais abrégé en JMR. Le texte est situé au début de la partie Printemps (Haru 春) du premier livre de son Koshichō, intitulé Koshichō kaidaiki 古史徽開題記 (Notes introductives aux preuves de l'Histoire de l'Antiquité) ; Hirata Atsutane zensh $\bar{u}$ 平田篤扸全 集 12, Hōbunkan shoten 法文官書店, 1914, p. 13-30.

19. Lu aussi Kamiyo hibumi no tsutahe 神字日文伝 (Commentaire sur le Hifumi en caractères du temps des dieux, 1819). Il y a un jeu de mot dans le titre de ce texte. À suivre les caractères chinois, hifumi signifie le «texte du soleil», mais hifumi, en lecture japonaise, sont les trois premières des quarante-sept syllabes dont se compose le texte. On pourrait le nommer «Un, Deux, Trois », car les premières syllabes seraient l'abréviation du dénombrement « un » (hi, de hitotsu), «deux » (fu de futatsu), «trois » (mi de mitsu); cf. note 77. Le reste de l'énumération ne présente apparemment aucun sens. Shinji hibumi den sera désormais abrégé en SHD.

20. Yashiro Hirokata travailla pour le bakufu, notamment aux relations avec la Corée. Il participa aussi indirectement à l'entreprise éditoriale que constituait le Gunsho ruijū 群書類從 (Recueil d'ouvrages à classement thématique). C'est lui qui fit part à Hirata de la rumeur concernant un jeune homme, Torakichi 寅吉, qu'on disait avoir vécu plusieurs années chez les Tengu 天狗, personnages mi-hommes mi-corbeaux dotés de pouvoirs extraordinaires. Yashiro Hirokata participa, aux côtés de Ban Nobutomo 伴信友 (1773-1846), aux entretiens avec le jeune prodige. Atsutane retrace son étrange enquête dans le Senkyō ibun 仙境異聞 (Récits inhabituels du Pays des Immortels), achevé en 1822 ; Wilburn Hansen, When Tengu Talk: Hirata Atsutane's Ethnography of the Other World, University of Hawaii Press, 2008.

21. Huainan zi 淮南子, chapitre 8, traduction de Rémi Mathieu, Huainan zi, Philosophes taoistes II, Gallimard, La Pléiade, 2003, p. 338. Rémi Mathieu rappelle la glose de Gao You dans Anthologie des 
mythes et légendes de la Chine ancienne, Gallimard, Connaissance de l'orient, 1989, p. 199. Autre récit de l'origine de l'écriture dans les Annales principales des trois souverains. Celles-ci furent ajoutées aux Mémoires historiques par Sima Cheng (Se-Ma Tcheng dans la transcription de Chavannes) au $\mathrm{VIII}^{\mathrm{e}}$ siècle de notre ère ; traduction d'Édouard Chavannes, dans Se-Ma Ts'ien (Sima Qian 司馬遷), Mémoires historiques, Adrien Maisonneuve, 1967, tome 1, p. 6: «Il (T'ai-huo P'ao-hi) inventa les textes écrits pour remplacer l'institution des cordes nouées ».

22. Platon réfutera le mythe pour en substituer un autre, celui de Thoth. Cf. Mario Vegetti, «Dans l'Ombre de Thoth, dynamique de l'écriture chez Platon », in Marcel Detienne (dir.), Les Savoirs de l'écriture en Grèce ancienne, Presses universitaires de Lille, 1988, p. 389-390.

23. Nihon shoki 日本書紀, tome $1,6^{\mathrm{e}}$ jour du $8^{\mathrm{e}}$ mois de la $15^{\mathrm{e}}$ année de l'empereur Ōjin : 「百済王 遣阿直岐（中略）阿直岐亦能讀經典（中略）於是天皇問阿直岐日如勝汝博士亦有耶（中

略）仍徵王仁也」; Shinpen Nihon koten bungaku zenshū 新編日本古典文学全集, Shōgakkan 小学 館, 1994, p. 482-485.

24. Kojiki 古事記：「又科賜百済國、若有賢人者貢上。故、受命以貢上人、名和雨吉師。即論 語十巻、千字文一巻、并十一巻、付是人即貢進」; Nihon koten bungaku taikei 日本古典文学大 系, Iwanami shoten, 1969, p. 248.

25. Sur cette question, se reporter aux travaux de Pascal Griolet.

26. Le personnage n'est connu que par ce passage de la préface du Kojiki qui ajoute simplement qu'il servait au palais. Comme souvent, faute de renseignement, on a beaucoup affabulé sur ce nom. Certains ont voulu en faire une femme, sorte de chamane détentrice des anciennes traditions sans la moindre preuve à l'appui.

27. Kojiki, op. cit. p. 46 :「度目誦口、拂耳勒心、即、勅語阿禮、令誦習帝皇日継及千代舊辭」

28. Selon le Nihon shoki, le prince assuma le pouvoir au nom de sa tante, l'impératrice Suiko 推古 天皇. On lui devrait d'avoir enclenché le processus qui allait mener à la constitution de l'État régi par les codes. On lui a également prêté nombre de fondations et d'ouvrages.

29. Il participa au côté du prince à la victoire des tenants du bouddhisme. Il faisait partie du clan des Soga qui domina la vie politique japonaise à la fin du $\mathrm{VI}^{\mathrm{e}}$ et au début du VII ${ }^{\mathrm{e}}$ siècle.

30. Cet ouvrage du début de l'époque de Heian reprend en dix livres la matière du Nihon shoki, du Kojiki et du Kogoshūi. Longtemps considéré comme véritablement antérieur au Kojiki, son caractère apocryphe fut démontré au cours de l'époque d'Edo par Tada Yoshitoshi 多田義俊 (1698-1756), puis par Ise Sadake 伊勢貞大 (1717-1784). Hirata Atsutane avança, dans son Koshichō kaidaiki, qu'il était l'œuvre d'un membre du clan des Mononobe. Cette hypothèse est maintenant généralement admise.

31. Ouvrage composé de fragments disposés selon l'ordre du Kojiki ou du Nihon shoki. Son but était de montrer l'ancienneté des prérogatives rituelles du clan des Inbe.

32. Dates inconnues. On sait seulement qu'il était actif à la fin du VIII ${ }^{\mathrm{e}}$ et au début du $\mathrm{IX}^{\mathrm{e}}$ siècle. Il appartenait au clan des Inbe, spécialisé dans les affaires rituelles.

33. 「上古世未有文字 貴賤老少口々相傳前言往行存而不忘書契以来不好談古」，Kogoshūi 古 語拾遺, Shinsen nihon koten bunko 4 新選日本古典文庫, Gendai shichōsha 現代思潮社, 1976, p. 192.

34. Cf. le Shōji jissō gi 声字実相義 (Le Sens véritable des lettres prononcées) et le Unji gi 吽字義 (Le Sens de la lettre hūm).

35. Voir dans le Hōbōgirin, à l'article A, le paragraphe consacré à l'Ajikan 阿字觀, «Inspection de la lettre A»; Sylvain Lévi, J. Takakusu, Paul Demiéville, Hōbōgirin, premier fascicule, Maison Franco-Japonaise, 1929-1930, p. 3. «La lettre a, étant la première, est l'esprit d'Éveil. Si on pratique l'Application en Inspectant cette lettre, on s'identifie au Substantiel du Corps d'Essence de Vairocana ".

36. Les 《lettres germes", shuji 種子 ou 種字, du sanscrit bijja, renferment, comme leur nom l'indique, une entité bouddhique qui se manifeste quand on prononce ou contemple la lettre. Ainsi la lettre A est le germe de Vairocana dans le plan de Matrice, mais aussi celui de la roue de 
la lune Aji getsurin shuji 阿字月輪種子, «parce que dans l'Inspection des trois ésotérismes on a fait de l'A une roue de Connaissance du Sans-Production originel de toutes les Essences»; Hōbōgirin, fascicule cité, p. 3.

37. Hartmund O. Rotermund (dir.), Religions, croyances et traditions populaires du Japon, Maisonneuve et Larose, 2000, p. 79-99.

38. Ce texte sera souvent cité par la suite sous le titre de Hijinsho 肥人書. On ignore ce que signifie exactement le terme de Hijin. Si l'on se fie aux caractères, il s'agirait des habitants de la province de $\mathrm{Hi}$, au nord-ouest de Kyūshū. Mais d'autres explications ont été avancées, notamment par Arai Hakuseki qui en faisait des habitants de la péninsule coréenne. Cf. infra, «L'écriture des dieux et l'écriture coréenne ».

39. 無文字者、豈可成卜哉者. Shaku Nihongi, Shintō taikei 神道大系, 1986, p. 9 du texte.

40. On a très tôt et longtemps attribué à Kūkai (Kōbō daishi 弘法大師) l'invention des kana et la composition du poème mnémotechnique qui commence par les signes I-ro-ha où chaque caractère du syllabaire apparait une seule et unique fois.

41. L'ouvrage est daté d'ordinaire de 1367, mais il est possible qu'il soit postérieur. Il fait partie des commentaires du Nihon shoki les plus cités jusqu'à l'époque d'Edo. Ce commentaire, qui se dit oral, se situe dans la tradition des "transmissions orales» (kuden 口伝), autrement dit des «transmissions secrètes» (hiden 秘伝) qui fleurissent à l'époque médiévale et sont minutieusement notées par écrit.

42. On le connaît comme auteur du Commentaire. Son nom le rattache au clan des ritualistes Inbe. Il a dû vivre pendant l'époque de Muromachi. À l'époque d'Edo, on s'est réclamé de lui pour fonder une nouvelle école du shintō, l'Inbe shintō 忌部神道.

43. 聖徳太子、以漢字附和字」; Shintō taikei 19 神道大系19, Koten chūshaku-hen 3 古典註釋編 3, Nihon shoki chūshaku chū 日本書紀註釋中, 1985, p. 3.

44. C'est ainsi qu'il est nommé dans l'édition du Shintō taikei, d'après le texte du fonds Yoshida conservé à la bibliothèque de Tenri. Dans la version conservée à l'Université de Kyōto, le texte se nomme Nihon shoki jindaishō日本書紀神代抄 (Bref commentaire du temps des dieux du Nihon shoki), et c'est souvent sous ce titre qu'il est cité. Ce qui peut amener une confusion avec l'ouvrage attribué au cinquième fils de Kanetomo, Kiyohara Norikata 清原宣賢, qui porte un titre très proche : Nihon shoki jindai no maki shō 日本書紀神代巻抄 (Bref commentaire des livres du temps des dieux du Nihon shoki) et qui est daté, lui, de 1536 ; Shintō taikei 20 神道大系20, Koten chūshaku-hen 4 古典註䆁編四, Nihon shoki chūshaku ge 日本書紀註䆁下, 1988, p. 5-6.

45. Ibid. p. 6:「カナ八弘法、カタカナ八、吉備ヨリト心得ソ」.Kibi, lettré et homme d'État de l'époque de Nara, n'est probablement pour rien dans l'invention des katakana.

46. 伏爔 (jap. Fukki), un des trois premiers souverains de la tradition chinoise. Il enseigna au peuple, dit-on, l'agriculture, la pêche et l'élevage. On lui prête aussi la création des hexagrammes, et donc de l'écriture.

47. On retrouve ici l'idée des lettres germes.

48. Ibid. p. 5-6 :「神代ニ八、何ノ字ヨ用ソ、カタカナヨモ、和字モナカラウニハ、何ソト云 二、神代ニ本アリ。秘ソ、サレトモ、伊冊二神ノ誓テ、矛ヨロシテ、國ヨ得テ、夫婦ノ会 アリテ、萬物ヨウムニ占アリ、ウラハ、トコカラテクルソト云ニ、陰陽五行ノ變カラ起

ソ、文字モ五行ノ變力ラ出来ソ、文字八、天地自然ノ易ソ。此自然ノ易テ、伏爔ノ俯仰シ

テ、一畫ヨ畫シテ、胸中一部ノ易ソ、サルホトニ、文字ト云物ハ一ソ、サレトモ、萬物ト

アラハルレハ、萬物ノカスニヨリテ、文字ノ數モ多ナルソ、一念不生ノ上ニ、忽然起テ、

三細（才）六塵トナリテ、八萬四千ノ大山トナルホトニ、其ヤウ二、文字モ多ナルソ、萬

物ノ心ヨ以テ、文字ノ多ナルハ、五行ノ變數ソ、五力變シテ、一萬三千七百九字ヤラ二ナ

ルソ。龜トソ。龜ヨヤクニ、上ハ火、下ハ水、左ハ木、右八金、中ハ土テ、コノイカミ、

スチリ、スクナニツイテ、一萬餘ノ字カテキタソ。神代ノ文字八、龜ノト（ウラ）テ知事

ソ」 
49. Kanetomo utilise ici le tableau des cinquante sons qui présentent les syllabes japonaises. La première ligne horizontale combine les différentes consonnes avec la voyelle A. Ce tableau fut établi sur la base des traités indiens de phonétique arrivés au Japon grâce au bouddhisme.

50. Ibid. p. 6:「日本（ヤマト）-ー、訓八不心得シテ、日本（ヒノモト）トコソ、和訓ナラ ハヨマウスニ、ヤマトトヨム八、何事ソト云ニ、ヤマトハ、吾國ノ大名ソ。此國ノ者力、 漢へ行二、國ノ名习問二、ナニトモ心得スシテ、ワカクニヤト云タニ、ヤト云ホトニ、ヤ 卜、ワトハ、通ホト二、此國ヨ、和卜漢ヨリ付タソ。此國八三界建立ノ源ソ。萬法ノ源 八、阿字ノ根本ソ。父母所（不）生ノ始八、阿八（ソ）。天地八ハシメモ阿ソ。アカサタ ナハマヤラハ、皆阿ソ。横ハトレモ阿字ソ。五十字ヨ置ニ、アタマナ字ハ、トレモ阿字ニ ユクソ。阿字ハ、ヤソ。アトハ, 通ソ。サルホト二、吾國ヨ、ヤマトト云力、自然二此國 ノ名ソ。有情非情ノ源ノ國チヤソ」.

51. Urabe shintō ge 卜部神道下, Shintō taikei 神道大系, Ronsetsuhen kyū 論説編九, 1991, p. 145-163. Pour une présentation sommaire de la question, voir Masuo Shin.ichirō 増尾伸一郎, “Shintō saishi to dōkyō 神道祭艳と道教》 (Les Célébrations du shintō et le taoïsme), in Sakade Yoshinobu 坂出祥伸 (dir.), Dōkyō no daijiten 道教大事典 (Grand dictionnaire du taoïsme), Shin jinbutsu ōraisha 新人物往来社, Bessatsu rekishi dokuhon 別冊歴史読本, 1994, p. 356-359. L'auteur montre que ces talismans sont empruntés à un ouvrage taoïste chinois, le Zhengtung daozang (jap. : Seitō dōzō) 正統道蔵 (Le magasin de la voie [Tao] légitime). Cet emprunt avait été signalé dès l'époque d'Edo par Usui Masatane 兒井雅扸 (dates inconnues), penseur du shintō de l'école de Shirakawa (Shirakawa shintō 白川神道) qui continuait la tradition des directeurs du ministère des Affaires des dieux.

52. Importante école opérant une synthèse entre le shintō médiéval et le confucianisme. Elle fut fondée par Yamazaki Ansai 山崎闇齊 (1616-1682).

53. Théorie que contesta Hirata Atsutane, SHD, vol. 1, p. 9.

54.「今神代の文字などといふ物あるは、後世人の偽作にて、いふにたらず」; Kojikiden 古事 記傅, livre 1, «Kakizama no koto» 文體の事 (De l'écriture). Motoori Norinaga zenshū 本居宣長全 集, volume 9, Chikuma shobō 筑摩書房, 1968, p. 17.

55. En appendice de son ouvrage Kana no motosue 假字本末 (L'Essentiel des kana), il écrivit un Jindaijiben 神代字辨 (Explication sur les caractères du temps des dieux). Ban Nobutomo zensh $\bar{u}$ 伴 信友全集, vol. 3, Kokusho kankōkai, 1909, p. 470-490.

56. 謗文, en lecture coréenne ŏnmun, " écriture populaire ", par opposition à l'écriture chinoise des lettrés. C'est l'écriture que l'on désigne actuellement sous le nom de hangŭl ou hangeul (écriture coréenne), dont le nom officiel est Hunmin chŏng’ŭm (jap. Kunmin sei.on 訓民正音: Sons corrects pour l'instruction du peuple), et dont l'utilisation a été promulguée en 1446 par le roi Sejong de la dynastie Yi. Hunmin chŏn'ŭm est d'abord le titre de l'opuscule qui présente la nouvelle écriture et indique ses principes (les caractères mères chamo 字母, qui distinguent les voyelles et les consonnes). Je remercie Vincent Grépinet et Arnaud Nanta pour leur aide dans la transcription des mots coréens.

57. (Coréen idu) 吏道, système d'écriture coréen correspondant aux man.yō gana japonais, c'est-àdire des caractères chinois pris phonétiquement, système utilisé au Japon dans le Man.yōshū, d'où leur nom.

58. Jindaijiben, op. cit. note 56, p. 470 :「あるが中に字體もおほかたさだかにて、みだりに作れ るものとはめざるが二體あるは、今朝鮮にて、浐文といひて用ふ國字の古體にて、吏道と いふものとぞ見えたる、さるをわがともがらのうひうひしきが中に、まことの神代のなり とおもひまどへるがあるに、かたはし論ひきかせたりへれば、いとどしくまどはしくなり ぬ」.

59. Cet ouvrage de Ch'oe Se-jin (jap. Sai Seichin) 崔世珍 fut republié en 1913, sous la colonisation japonaise donc, à Séoul (Keijō), dans la Collection coréenne Chōsen sōsho 朝鮮叢書. La collection coréenne des études orientales a réédité deux versions de cet ouvrage conservé au Japon, l'un au Hieizan 比疅山文庫, l'autre à la bibliothèque centrale de l'université de Tōkyō 東京大学中央困 
書館. Dans cette dernière, les lectures sino-japonaises et japonaises ont été rajoutées en katakana. Hunmong chahoe 訓蒙字會 Tongyanghak ch'ongsŏ 東洋學鋷書第一輯, Tan'guk taehakkyo pusŏl Tongyang yŏn'guso 檀國大學校附設 東洋學研究所, (1971) 1983. Je remercie Laurent Quisefit de m'avoir procuré cet ouvrage.

60. Ce n'est pas sans raison qu'on le rattache à l'École des preuves (Kōshōgaku 考証学), courant apparu en Chine à la fin des Ming.

61. Lettré au service du fief de Fukuoka qui écrivit sur un nombre incroyable de sujets depuis la botanique jusqu'à l'hygiène de la vie quotidienne. À la fin de sa vie, il récusa l'orthodoxie confucéenne de l'école de Shushi.

62. Lettré disciple d'Ogyū Sorai 荻生徂徠 (1666-1728), connu pour son traité sur l'économie, Keizairoku 経済録, mais aussi pour ses attaques contre le shintō.

63. Lettré issu d'une famille spécialisée dans la voie des Lettres. Précepteur du futur empereur Go-Sanjō, il eut une carrière brillante et écrivit une œuvre abondante.

64. Fonctionnaire lettré de l'époque de Heian qui fut chef du département du palais.

65. Autre nom de Kaibara Ekiken 貝原益軒.

66. L'ouvrage est cité cinq lignes plus loin sous le titre de Hakozaki gūki 箱崎宮記 (Écrits sur le sanctuaire de Hakozaki), titre par ailleurs retenu par le Kokusho sōmokuroku (Catalogue général des livres japonais) : "Dans notre royaume la première fois que l'on utilisa l'écriture en remplacement des cordes nouées ce fut sous ce règne [d'ōjin]»「我朝始書文字。代結縄之政。

即創於此朝」. L'allusion aux cordes nouées vient de Chine, cf. note 22.

67. SHD, p. 6:「我邦上古無文字（中略）以為上世有國字者妄説也」.

68. Ibid. Dazai est nommé par son nom personnel Jun 純. L'ouvrage cité est le Wadoku yōryō 和讀 要領 (L'essentiel de la lecture japonaise) : «qu'il n'y ait pas d'écriture dans notre pays a été clairement expliqué par les sages antérieurs »「吾國に文字なき事は。先賢の説明白なり」.

69. Consultation kanmon 勘文 de Shōtai 4 昌泰4 (901)：「上古之事皆出口傳。故代々之事應有 遺漏」.

70. SHD, p. 7 : 「兩儒者の論ずるところ。無稽の甚しきなり」.

71.「貝原太宰が輩。日本に生まれながら、其の學ぶ所に僻して。我國を鄙むるは。固徆の 甚しきなり。舊き神社には。上古の神字今に殘りて。儼然として存在するなり」.

72. Cf. l'article de Francine Hérail, «Arai Hakuseki et les origines de l'histoire », Cipango, nº 2, février 1993, p. 165-189.

73.「我國ノ神代二亀ヨ灼テソノ兆ヨナセシハ後ノ代ノ文字ノ起レル始也トイハンハアシカ ラジ」. Arai Hakuseki zenshū 新井白石全集 (Euvres complètes d'Arai Hakuseki), vol. 4, Dōbun tsūkō 同文通考 livre 2, Yoshikawa Hanshichi (dir.) 吉川半七, 1906, p. 439.

74. Par exemple, SHD « Annexe sur les caractères douteux », p. 3. Atsutane présente un document de transmission attribué à Yamazaki Suika, Yamazaki suika ō kirigami den 山崎垂加翁切紙傳. Si Atsutane rejette ce type de caractère, c'est probablement parce qu'ils ne présentaient pas un véritable système d'écriture.

75. Ouvrage en 72 livres, imprimés entre 1676 et 1679, ce « sutra » se réfère bien évidemment au Sendai kuji hongi de l'époque de Heian dont nous avons dit plus haut que les érudits de l'époque d'Edo vont dévoiler le caractère apocryphe (cf. note 31). Se situant dans le courant d'unicité des trois enseignements (bouddhisme, confucianisme et shintō), le Sendai kuji hongi daiseikyō fut interdit par le bakufu en 1681. Il est actuellement disponible dans la collection du Zoku Shintō taikei. Vol. 36-39, 1999.

76. Hito pour Hitotsu (un), fukumu pour futatsu (deux), michi pour mitsu (trois), yoshi pour yotsu (quatre), inochi pour itsutsu (cinq), mukuhi pour mutsu (six), na pour nanatsu (sept), yasashi pour yattsu (huit), ko pour kokonotsu (neuf), tomogara pour tō (dix), moto pour momo (cent); cf. note 20.

77. Itsuhari fumi 偽書; SHD, p. 18, où Atsutane le cite sous le titre de Daiseikyō. Les caractères sont pris pour la première syllabe de leur lecture japonaise. 
78. SHD, p. 6:「此説は、かの黒瀧の潮音が偽り作れる舊事大成經といふ物に記せる、妄説に 本づきて言ひ出たる説なり」.

79. Ou Kaneyoshi (1402-1481), homme de cour, qui fut ministre des Affaires suprêmes et grand chancelier. Il conseilla aussi les shōgun Ashikaga. On trouve dans son œuvre des traités sur les cérémonies et les usages de la cour et un commentaire du Nihon shoki, le Nihon shoki sanso 日本書 紀纂疏 (Recueil critique [des commentaires] du Nihon shoki).

80. Kana nihongi 假名日本記. Notons que le ki/gi est noté ici par 記 et non par 紀, comme dans le Nihon shoki que nous connaissons.

81. JMR (cf. note 18, p. 15) :「此文に古本と云るは、假名日本記をいひ、後本と云るは、今在 る日本書紀と云るなり、其古本重みする趣をみて、今の書紀より古き本なること知るべ

し」.

82. Magana 眞假字; JMR, p. 15:「私記釋紀に引用たる假名日本記は。其一部専用假名倭言と 云る方にて、その記たる體は。大抵古事記と同じ状にて。彼記よりもなほ古びて。多く眞

假字に書る書なりけり」. Les magana sont les caractères chinois utilisés pour leur son. On parle le plus souvent aujourd'hui de man.yō gana.

83. JMR, p. 17：「その假名には。漢字の假名と、和字の假名と。伊呂波の假名と。三種ある 事を示し」.

84. JMR, p. 18: 二説を合せて考るに。其事物の象形を畫たると。ロに出る音々の印に作る 假字との二種になむ有へる」。

85. SHD, p. 1 : 「然る怯き倫は、今云ふ限りに非ず」.

86.「眞字をのみ視れば。朝鮮のいはゆる浐文といふ字に似たるに。此はもと彼の謗文を採 て作れるには非じかと」。

87. Ibid. : 「朝鮮の浐文といふは。我が神世の文字の。古く彼の國にも傳はりたるを。彼の國 人のさかしらを加へて。作り改めたる物ならむと」.

88. L'un appartenait à Ban Nobutomo, l'autre fut rapporté de Corée par Katō Kiyomasa 加藤清正 (1562-1611), grand daimyō du temps de Toyotomo Hideyoshi et l'un des principaux généraux des campagnes de Corée.

89. Cf. note 55 .

90.「SHD, p. 10: 言へれども。強言なり。賀茂道淵を始め。宣長は。皇國の道を開くと云へ ども。漢意はなれず。和漢混雑なる故に。明に知らず。強言をいひ出して。世の人を惑は す事あり。篤胤云、縣居大人、鈴屋大人共に、神代に文字なしと言はれしは、考への廘か りしなれど、漢意はなれず」。

91. SHD, p. 14:「右神代四十七音字者。天屋根命之眞傳也。對馬國卜部阿比留氏内々傳之可 秘々々焉」.

92. Il oublie de préciser que Tsushima se trouve fort près de la Corée et a entretenu des rapports réguliers avec les Coréens. Voir l'article de Guillaume Carré : http://cipango.revues.org/1118.

93. Atsutane reprendra sa réflexion sur les cinquante sons à l'aide de l'écriture des dieux dans un autre traité, le Koshi honjikyō 古史本辭經 (Les Règles des caractères fondamentaux de l'Histoire de l'Antiquité), particulièrement dans le premier livre. Hirata Atsutane zenshū, op. cit., tome 12, Hōbunkan shoten, 1914.

94. Jap. : Tōkoku tsūkan 東國通鑑 (Miroir du Pays de l'Est), histoire de la Corée compilée en 1484 par Sō Kō-jōng 徐居正 (1420-1488) sous le règne de Sŏngjong (Seisō) 成宗 (1469-1494).

95. L'Illustration des trois règnes [Ciel, Terre, Homme] au Japon et en Chine est un dictionnaire encyclopédique illustré en 105 livres (en réalité 81) compilé en 1712 par le médecin Terashima Ryōan 寺島良安 (dates inconnues).

96. SHD, p. 30:「佊の地は、元より訓語の國なれば、漢字よりは、皇國字を用ひ習ひけむこ と、實に尤もなる事にざりける」.

97. SHD, p. 32:「皇國の正しき字は傳へながら。年を重ね世を經るまにまに。古傳の用格を 失へるを。強に其字に原づき。悉量 章を附會して。字を製り増したる故に。かく事痛き 拙き物とは成にけむ」。 
98. SHD, p. 33:「字音の正しきとは。ウヨ羊ワ。ユヨイエヤの二行も。紛はしき事なく。 正しく作ちて。オヨイ立よく別りて。其所屬のいと正しきを以て言ふなり。浐文によりて 製れる物ならましかば。如斯く正からめや。其はオヨイキエ卫の差別を知らで無用なる事 の如く思へるは舊き事にて。七百年ばかり以來は。殊に然有りしを。近ごろ契沖法師が明 らめたるより。世の人も。此差別を正すべき事を知りたれば。日文もし契沖僧が。此事を 明らめざる以前に。僞り作れるならむには。此差別も立まじく」。

99. Op. cit. p. 39 et $s q$.

100. Kang Hang laissa un livre sur son expérience japonaise, le Suŭn kanyangnok 睡隠看羊録, Suŭn (Suiin) étant son nom de lettré. Fujiwara Seika est souvent considéré comme le premier véritable lettré confucéen japonais. Il fit sortir le confucianisme des Song des monastères zen pour le propager dans la société civile.

101. Probablement l'une des trois suivantes: 1643, 1655, 1682. D'ordinaire, les ambassades logeaient au Honkokuji 本國寺, mais en 1719, la $9^{\mathrm{e}}$ séjourna au Honnōji, ce qui fut sans doute le cas d'une des précédentes.

102. Kim Moon Gil, op. cit. p. 39, faisant référence à Yi Chin-Hŭi (Ri Shinki) 李進熙, Richō no tsūshinshi 李朝の通信使 (Les ambassades de la dynastie Yi), Kōdansha 講談社, 1976.

103. Pour communiquer avec les Coréens, Hakuseki semble avoir utilisé le chinois plutôt que le coréen. Sur ce contact entre Hakuseki et l'ambassade coréenne, voir l'article de Vincent Grépinet : http://cipango.revues.org/1120.

104. Cet ouvrage dont je n'ai pas retrouvé la date d'achèvement, fut republié en 1883 par le ministère des Affaires étrangères.

105. 昆陽漫録 (Essai au fil du pinceau de Kon.yō), 1753. L'ouvrage est consultable dans la Collection des essais du Japon, Nihon zuihitsu taisei 日本随筆大成, $1^{\text {re }}$ période, vol. 20 第一期、巻 20 , Yoshikawa kōbunkan 吉川弘文館, (1976) 2007.

106. Cf. Ryu Sang-hŭi 柳尚熙, Edo jidai to meiji jidai no nihon ni okeru chōsengo no kenkyū 江戸時代 と明治時代の日本における朝鮮語の研究, Seikō shobō 成甲書房, 1980, cité par Kim Moon Gil, op. cit. p. 40. Kim attribue curieusement cet ouvrage à Yi Chin-Hŭi, qu'il évoque dans la note précédente.

107. Cf . François Macé, "Le shintō et christianisme, une rencontre improbable », in La Rencontre du Japon et de l'Europe, image d'une découverte, CEJA, POF, 2007, p. 176 et sq.

108. JMR, p. 19:「また西洋人も甚く漢文字を笑ひて、漢人は餘りに字を多く製りて生涯己が 國字を知盡すこと能はずと云へるをも思ふべし」。

109. Je pense au Uhetsufumi 上記, ou plus récemment au Hotsuma tsutahe ホツマ伝. J'en reparlerai en conclusion.

110. Léon de Rosny, Histoire des dynasties divines, Paris, Ernest Leroux, 1887.

111. Cf. Pascal Griolet, La modernisation du Japon et la réforme de son écriture, Paris, POF, 1985, p. 45-74.

112. Hiraiwa Yoshiyasu 平岩愃保, «Nihon moji no ron 日本文字の論》 (De l'écriture japonaise ), Rikugō zasshi 六合䧱誌, $\mathrm{n}^{\circ}$ 50, 1885 ; cité par Kim Moon Gil, op. cit. p. 19-26. Hiraiwa est aussi l'auteur d'un ouvrage intitulé Waga kokutai to kirisutokyō 我が國體と基督教 (Notre essence nationale et le christianisme), publié à compte d'auteur à Shizuoka en 1896.

113. Cité par Kim Moon Gil, op. cit. p. 12. Kim Yun-gyŏng 金允経, Chosŏn munhak kŭp ŏhak sa 朝鮮 文学及語学史, Sŏn'il inswaejo 鮮一印刷所, Tanki 檀紀 4279 (1946). En se référant à l'ère coréenne qui commence avec Tan'gun 檀君 (2333 av. notre ère), les Coréens surpassent l'ère impériale japonaise de près de 2000 ans. Mais la date donnée ici est postérieure à l'occupation japonaise. Il s'agit probablement de la première édition d'un texte qui n'avait pu être publié sous l'occupation.

114. 林ホシュ Sō Hoshu, «Hanguru wa seisō daiō izen ni mo atta ハングルは世宗大王以前にも あった»(Le Hangŭl existait avant le roi Sejong le grand), Hiroba 広場, nº 1, 1984, cité par Kim Moon Gil, op. cit. p. 13-14. 
115. «Iwayuru jindai moji no ron 所謂神代文字の論 》, publié en trois livraisons en 1952-3 dans la revue Geirin 藝林, $4^{\mathrm{e}}$ vol. L'auteur, premier président de l'université shintō de Kōgakkan 皇学 館大学, a pourtant fait partie en 1941 de la commission d'enquête sur les saintes traces de l'origine de la nation (plus platement les vestiges du règne du premier et légendaire empereur humain) Chōkoku seseki chōsa 肇國聖蹟調査. Il a aussi publié en 1940 un ouvrage sur Hirata Atsutane que je n'ai pas pu consulter.

116. Rédacteur en chef des Éditions Jiyū kokuminsha 自由国民社 qui travailla sur des ouvrages comme le Gendaiyōgo no kisochishiki 現代用語の基礎知識 (Connaissances fondamentales sur le vocabulaire usuel contemporain, une sorte de Quid). Il se passionna pour le Hotsuma tsutae après avoir vu une photographie du manuscrit chez un bouquiniste de Kanda.

117. The Hotsuma Legend-Path of Ancestoirs, traduit par Andrew Driver, Japan translation Centre, 1979.

118. L'auteur crédité n'est autre que le dieu Ohotataneko no mikoto 大田田根子命. Édité par Hotsuma kankōkai ホツマ刊行会, 1993, prix indiqué 30000 yens.

119. Né en 1930, professeur à l'université de Kumamoto jusqu'en 1970, il est l'auteur de nombreux livres sur l'Antiquité japonaise tel Dōtaku no nazo 銅鐸の謎 (L'énigme des cloches dōtaku). Le livre évoqué ici est Jindai moji no nazo 神代文字の謎, (L’énigme de l'écriture du temps des dieux), Tōgensha 桃源社, 1979.

120. Né en 1937, diplômé d'histoire de la faculté de littérature de l'Université de Tōkyō : GishokōUmareta kisho « uetsufumi » no nazo 偽書考一埋まれた奇書 "上記" の謎 (Réflexion sur un faux : l'énigme du Uetsufumi, un étrange livre enfoui), Tōgensha 桃源社, 1980.

121. Asahi shinbun 朝日新聞 (édition internationale), 23 avril 2010, p. 6.

\section{RÉSUMÉS}

$\mathrm{Au} \mathrm{XIX}^{\mathrm{e}}$ siècle, Hirata Atsutane s'évertue à prouver l'existence d'une antique écriture indigène, antérieure à l'adoption des caractères chinois : «l'écriture des dieux ».

In the 19th century, Hirata Atsutane strived to demonstrate the existence of an ancient native writing, prior to the adoption of Chinese characters: "writing of gods' age".

\section{INDEX}

Mots-clés : Hirata Atsutane (1776-1843), Motoori Norinaga (1730-1801), shintō, japonais (langue), coréen (langue), jindai moji, Kokugaku

Thèmes : philologie, histoire

Index chronologique : Edo (1603-1867)

キーワード : Hirata Atsutane 平田篤胤 (1776-1843), Motoori Norinaga 本居宣長 (1730-1801), shintō 神道, nihongo 日本語, kankokugo 韓国語, jindai moji 神代文字, Kokugaku 国学, Kankoku 韓国, Edo jidai 江戸時代 (1603-1867), bunkengaku 文献学, rekishi 歴史

Keywords : Hirata Atsutane (1776-1843), Motoori Norinaga (1730-1801), shintō, Korean (Language), jindai moji, Kokugaku, Korea, Edo Period (1603-1867), Philology, History

Index géographique : Corée 